\title{
Article
}

\section{In Situ Observation of Microstructural and Inclusions Evolution in High-Strength Steel Deposited Metals with Various Rare Earth Pr Contents}

\author{
Tianli Zhang ${ }^{1, *}$, Weiguang Wang ${ }^{1}$, Yiming Ma ${ }^{2}$, Naiwen Fang ${ }^{2}$, Sanbao Lin ${ }^{3} \mathbb{D}$, Zhuoxin Li $^{4}$ and Sindo Kou ${ }^{5}$ \\ 1 School of Materials Engineering, Shanghai University of Engineering Science, Shanghai 201620, China; \\ wwg14579@163.com \\ 2 Harbin Welding Institute Limited Company, Harbin 150028, China; myiming246@sina.com (Y.M.); \\ naiwen20@163.com (N.F.) \\ 3 State Key Laboratory of Advanced Welding and Joining, Harbin Institute of Technology, Harbin 150001, \\ China; sblin@hit.edu.cn \\ 4 College of Materials Science and Engineering, Beijing University of Technology, Beijing 100124, China; \\ zhxlee@bjut.edu.cn \\ 5 Department of Materials Science and Engineering, University of Wisconsin, Madison, WI 53706, USA; \\ kou@engr.wisc.edu \\ * Correspondence: zhangtianli925@163.com
}

Citation: Zhang, T.; Wang, W.; Ma, Y.; Fang, N.; Lin, S.; Li, Z.; Kou, S. In Situ Observation of Microstructural and Inclusions Evolution in

High-Strength Steel Deposited Metals with Various Rare Earth Pr Contents. Materials 2022, 15, 1257. https:// doi.org/10.3390/ma15031257

Academic Editor: Hansang Kwon

Received: 20 December 2021

Accepted: 28 January 2022

Published: 8 February 2022

Publisher's Note: MDPI stays neutral with regard to jurisdictional claims in published maps and institutional affiliations.

Copyright: (C) 2022 by the authors. Licensee MDPI, Basel, Switzerland. This article is an open access article distributed under the terms and conditions of the Creative Commons Attribution (CC BY) license (https:// creativecommons.org/licenses/by/ $4.0 /)$

\begin{abstract}
The evolution of austenite, acicular ferrite, upper bainite and martensite, and the nucleation of inclusions in the microstructure of high-strength steel deposited metals, was systematically investigated using three kinds of A5.28 E120C-K4 metal-cored wires with various rare earth Pr contents. Grain structure evolution in the process of high temperature, dispersoid characteristics of inclusions and the crystallographic characteristics of the microstructure were assessed. Compared with no addition of $\operatorname{Pr}_{6} \mathrm{O}_{11}$, adding $1 \% \mathrm{Pr}_{6} \mathrm{O}_{11}$ resulted in refined, spheroidized and dispersed inclusions in the deposited metal, leading to an increase in the pinning forces on the grain boundary movement, promoting the formation of an ultra-fine grain structure with an average diameter of $41 \mu \mathrm{m}$. The inclusions in the deposited metals were Mn-Si-Pr-Al-Ti-O after Pr addition; the average size of the inclusions in the Pr-containing deposited metals was the smallest, while the number and density of inclusions was the highest. The size of effective inclusions (nucleus of acicular ferrite formation) was mainly in the range of $0.6-1.5 \mu \mathrm{m}$. In addition, the content of upper bainite decreased, while the percentage of acicular ferrite increased by $24 \%$ due to the increase in the number of effective inclusions in the Pr-containing deposited metals in this study. This study shows that the addition of $1 \% \operatorname{Pr}_{6} \mathrm{O}_{11}$ is efficient in achieving fine interlaced multiphase with an ultrafine-grained structure, resulting in an enhancement of the impact toughness of the deposited metal.
\end{abstract}

Keywords: high-strength steel; rare earth Pr; deposited metal; in situ observation; microstructure; mechanical properties

\section{Introduction}

The use of 690-1200 MPa high-strength steel is widespread in industries with extremely high safety requirements, such as the petrochemical industry, nuclear power, aerospace and rail transit. However, the corresponding welding consumables with matched strength and toughness are few, which limits its further application. In the welding of high-strength steel, the higher the strength level of the deposited metals, the more likely the occurrence of hydrogen embrittlement. At present, the microstructure of high-strength steel deposited metal can be optimized by adjusting the composition and proportion of alloying elements, so that its strength and toughness can be improved. Therefore, it is extremely important to study the effects of alloying elements on the microstructure and mechanical properties of highstrength steel deposited metals and the development of matched welding consumables [1-3]. 
Currently, the research on improving the strength and toughness of high-strength steel deposited metal mainly focuses on microalloying elements such as $\mathrm{Nb}, \mathrm{Ti}, \mathrm{Cu}, \mathrm{Ni}$ and $\mathrm{Zr}$. Fine inclusions can promote the formation of acicular ferrite (AF); inhibit the growth of bainite, ferrite side-plate, and proeutectoid ferrite in the austenite grains; affect the diffusion of other elements and the nucleation and growth of new phases and induce the change in microstructure and properties of the high-strength steel deposited metals [4-9]. During the welding process, the original austenite grains of the deposited metal with high carbon content grow rapidly, and a large amount of upper bainite (UB) and a small number of AF can be formed during the cooling process, so as to reduce the mechanical properties of deposited metals. In addition, the properties can be improved by preheating before welding, and a reduction in heat input and post-welding heat treatment [10-13]

Rare earth elements can spheroidize and refine inclusions in high-strength steel deposited metals, which acts as the pinning of grain boundaries to restrain grain coarseness. In the cooling process, rare earth inclusions can induce the formation of AF, thereby improving the toughness of deposited metals. Therefore, the mechanical properties of high-strength deposited metal can be improved by controlling the content of rare earth elements to refine grains, and by controlling the quantity, size, shape and composition of inclusions to promote the formation of AF [14-16].

Most current studies focus on high-strength steel deposited metal microstructures after solidification, but have not dealt with the real-time observation of the dynamic transformation of austenite, ferrite, bainite and martensite in high-strength steel deposited metals at high temperature. In this research, the starting point of phase transformation was not defined, and the grain nucleation growth as well as migration were not observed. The use of a high-temperature laser scanning confocal microscope for in situ observation of microstructure at high temperature can solve the above problems [6,17]. In this paper, in situ observation was carried out using a high-temperature confocal microscope to study the effect of $\operatorname{Pr}_{6} \mathrm{O}_{11}$ on the growth behaviors of austenite, ferrite, bainite and martensite in the microstructure of $800 \mathrm{MPa}$ high-strength steel deposited metals. The chemical composition, microstructure, mechanical properties and nucleation of inclusions in the deposited metals were also discussed. The aim of this paper is to study the effect of Pr on the deposited metals so as to enrich and improve the theory on the effect of rare earth in welding metallurgy.

\section{Materials and Methods}

Three kinds of self-developed high-strength steel metal-cored wires $(1.2 \mathrm{~mm}$ in diameter), designated as wire nos. 1-3, were used to prepare deposited metals by welding according to the AWS standard A5.28 E120C-K4 [18]. The addition of $\operatorname{Pr}_{6} \mathrm{O}_{11}$ was $0 \%$ weight percent with wire no. 1, $1 \%$ weight percent $\operatorname{Pr}_{6} \mathrm{O}_{11}$ with wire no. 2, and $2 \%$ weight percent $\mathrm{Pr}_{6} \mathrm{O}_{11}$ with wire no. 3 . The welding parameters are shown in Table 1 . The chemical composition of the deposited metals are shown in Table 2. The chemical compositions of deposited metals were determined with a Q4 optical emission spectrometer. The mechanical testing was conducted to ASTM A370-2019 standards. After preparing the standard specimens, the mechanical properties of the deposited metals were tested with a WAW-6000 tensile test machine, and the yield strength, tensile strength and elongation were recorded. The Charpy V-notch impact test was performed by an JB30B impact testing machine after the impact specimens were cooled to $-40^{\circ} \mathrm{C}$.

From the position parallel to the surfacing surface on each deposited metal, 6 cylindrical specimens were cut to $6 \mathrm{~mm}$ in diameter and $3 \mathrm{~mm}$ in length. One of the specimens was ground and polished to be the metallographic specimen etched by $5 \%$ nital. The microstructures of the deposited metals were observed by scanning electron microscopy (SEM) with a Hitachi S-3400N microscope, and the inclusions in deposited metals were analyzed by energy dispersive spectrometer (EDS) analysis. Selecting the impact sample for metallographic analysis, a sample was cut with a thickness of $5 \mathrm{~mm}$ and a length and width of $10 \mathrm{~mm} \times 10 \mathrm{~mm}$ below the fracture surface. After water grinding and polishing, the surface of the sample had no oxide layer and continuous corrosion pits. The surface of 
the sample was electropolished with chloric acid alcohol solution to eliminate the surface processing strain layer. The operating voltage during electrolysis was $12 \mathrm{~V}$ and the time was $15 \mathrm{~s}$. The orientation relationship and crystallographic grain size of microstructure was examined by $20 \mathrm{KV}$ voltage electron backscatter diffraction (EBSD) with a Tescan LYRA3 XMH SEM. The remaining 5 specimens were polished to be the high temperature metallographic specimens and mounted in an alumina crucible. The in situ observation was carried out by high-temperature laser scanning confocal microscopy with a Lasertec VL2000DX-SVF17SP and an Yonekura infrared image furnace. The specimens were heated to $1500{ }^{\circ} \mathrm{C}$ at a rate of $5{ }^{\circ} \mathrm{C} / \mathrm{s}$ and then cooled at a rate of $5{ }^{\circ} \mathrm{C} / \mathrm{s}$ to form austenite, ferrite, bainite and martensite microstructures. The photographs were taken at a speed of 15 images per second during the simulated thermal cycle. The OLYCIA-M3 quantitative analysis software was used to perform quantitative statistical analysis on the microstructure and inclusions of deposited metals.

Table 1. Welding parameters used in experiments.

\begin{tabular}{ccccccc}
\hline $\begin{array}{c}\text { Current } \\
\text { /A }\end{array}$ & $\begin{array}{c}\text { Voltage } \\
\text { /V }\end{array}$ & $\begin{array}{c}\text { Wire } \\
\text { Stick-Out } \\
/ \mathbf{m m}\end{array}$ & $\begin{array}{c}\text { Shielding } \\
\text { Gas } \\
\text { /\% }\end{array}$ & $\begin{array}{c}\text { Gas Flow } \\
\text { Rate } \\
/ \mathbf{L} \cdot \mathbf{m m}^{-\mathbf{1}}\end{array}$ & $\begin{array}{c}\text { Welding } \\
\text { Speed } \\
/ \mathbf{c m} \cdot \mathbf{m i n}^{-\mathbf{1}}\end{array}$ & $\begin{array}{c}\text { Pre-Heat/Inter- } \\
\text { Pass Temp. } \\
/{ }^{\circ} \mathbf{C}\end{array}$ \\
\hline 240 & 30 & 16 & $80 \mathrm{Ar}+20 \mathrm{CO}_{2}$ & 20 & 28 & 150 \\
\hline
\end{tabular}

Table 2. Chemical composition of deposited metals (wt.\%).

\begin{tabular}{ccccccccccccc}
\hline No. & C & Mn & Si & P & S & Cr & Ni & Mo & Pr & Al & Zn & Ti \\
\hline 1 & 0.038 & 1.891 & 0.424 & 0.013 & 0.008 & 0.405 & 2.122 & 0.625 & 0 & 0.011 & 0.0053 & 0.016 \\
2 & 0.049 & 2.182 & 0.533 & 0.012 & 0.008 & 0.492 & 2.258 & 0.882 & 0.011 & 0.015 & 0.002 & 0.018 \\
3 & 0.046 & 2.016 & 0.520 & 0.013 & 0.008 & 0.462 & 2.060 & 0.872 & 0.015 & 0.016 & 0.002 & 0.018 \\
\hline
\end{tabular}

\section{Results and Discussion}

\subsection{Grain Growth Behavior during the Transformation of Austenite}

The in situ observation of austenite grain growth in the deposited metal of highstrength steel without $\operatorname{Pr}_{6} \mathrm{O}_{11}$ is shown in Figure 1. The inclusions agglomerate in the deposited metal as shown in Figure 1a. As the temperature decreases, small austenite grains appear, as shown in Figure 1b. Small grain (grain no. 1) aggregates and swallows the surrounding austenite grains (grains nos. 2-3), to form a large grain (grain no. 4). During the nucleating process of austenite with the addition of $1 \% \operatorname{Pr}_{6} \mathrm{O}_{11}$ as shown in Figure 2, the inclusions become dispersed in the grain boundaries and act as a pinning to prevent the extension of austenite grains in different directions, due to the refining effect of the rare earth element Pr on the inclusions. As a result, the growth of austenite grains was hindered, and the grains are significantly refined. With an addition of $2 \% \operatorname{Pr}_{6} \mathrm{O}_{11}$ as shown in Figure 3 , the quantity of inclusions is significantly reduced. The austenite grains nucleate first and then extend in different directions. Due to the lack of inclusion pinning, the growth of austenite grains is not restricted, so the grains are obviously coarsened.

From the statistical results of the average austenite grain size in Figure 4 , it can be seen that with the increase in $\operatorname{Pr}_{6} \mathrm{O}_{11}$, the average austenite grain size first decreases and then increases.

When $\operatorname{Pr}_{6} \mathrm{O}_{11}$ was not added, the average size of the austenite grains reached $129 \mu \mathrm{m}$, because the growth of the grains was not restricted due to the agglomeration of inclusions. When $1 \% \operatorname{Pr}_{6} \mathrm{O}_{11}$ was added, the addition of rare earth elements refined and spheroidized the inclusions, making them dispersed in the deposited metal. The inclusions have a pinning effect on the austenite grain boundaries, so they limit the growth of austenite grains [19]. The average size of austenite grains was $41 \mu \mathrm{m}$. When $2 \% \operatorname{Pr}_{6} \mathrm{O}_{11}$ was added, the decrease in oxygen content in the deposited metal led to the reduction of nucleation sites of inclusions, which made the growth of austenite unrestricted, and the average size of austenite grains increased to $53 \mu \mathrm{m}$. 
The $-40{ }^{\circ} \mathrm{C}$ impact toughness of the depositded metal is shown in Figure 5 . With the addition of $\operatorname{Pr}_{6} \mathrm{O}_{11}$, the impact toughness increased at first and then decreased. When 1\% $\mathrm{Pr}_{6} \mathrm{O}_{11}$ was added, the impact toughness reached the maximum of $72 \mathrm{~J}$.
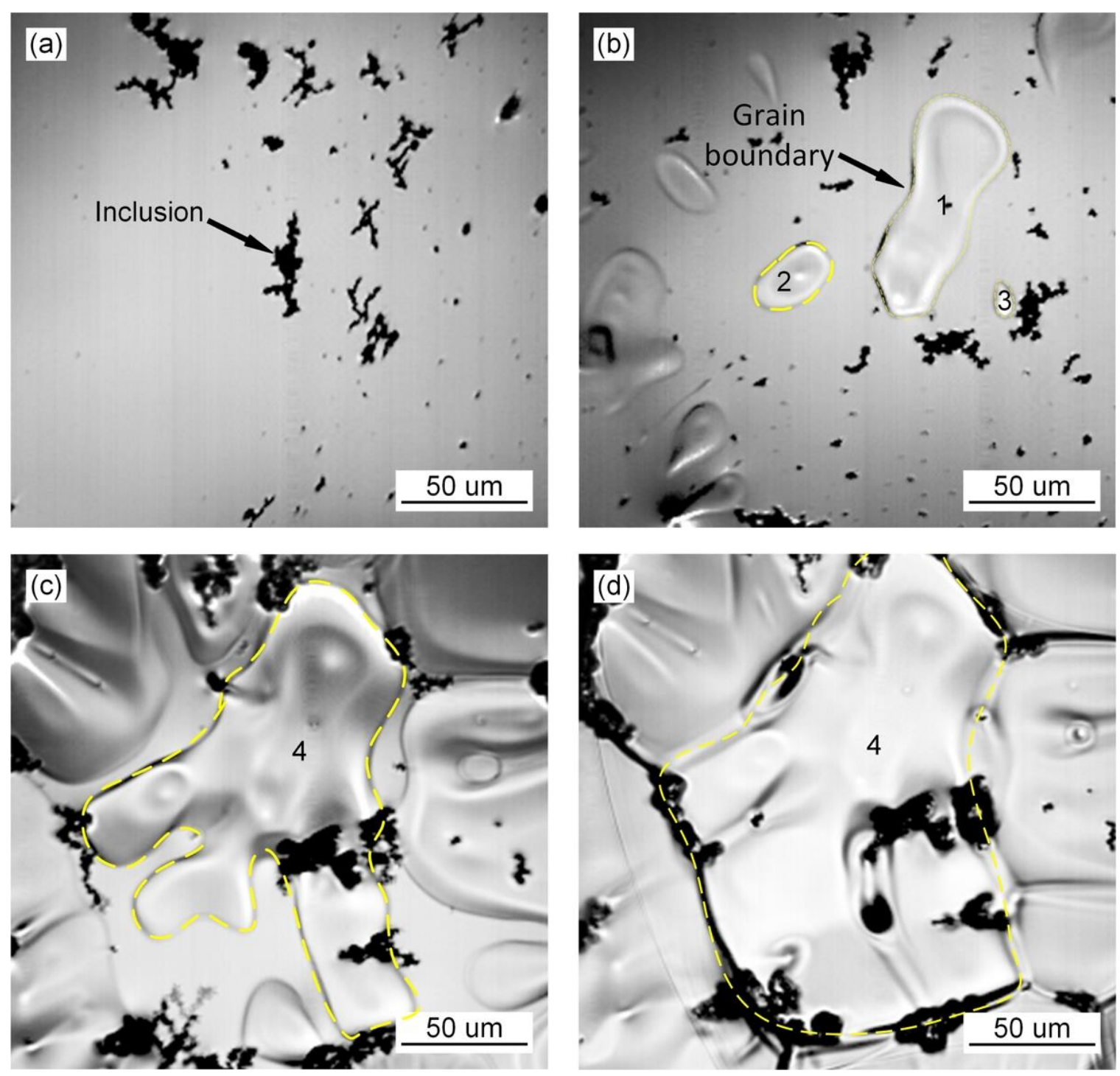

Figure 1. In situ observation of growth process of austenite at $0 \% \operatorname{Pr}_{6} \mathrm{O}_{11}$ : (a) $369.4 \mathrm{~s}, 1480.7^{\circ} \mathrm{C}$; (b) $373.59 \mathrm{~s}, 1460.5^{\circ} \mathrm{C}$; (c) $379.97 \mathrm{~s}, 1423.6^{\circ} \mathrm{C}$; (d) $386.95 \mathrm{~s}, 1378.3^{\circ} \mathrm{C}$.

Figure 6 shows the tensile strength and yield strength curves of the deposited metals with the addition of various $\operatorname{Pr}_{6} \mathrm{O}_{11}$ contents. With the addition of $\operatorname{Pr}_{6} \mathrm{O}_{11}$ from $0 \%$ to $2 \%$, the strength of weld metal gradually decreased. With the addition of $2 \% \operatorname{Pr}_{6} \mathrm{O}_{11}$, the tensile strength of the weld metal decreased from the initial value of $843 \mathrm{MPa}$ to $814 \mathrm{MPa}$, and the yield strength decreased from $793 \mathrm{MPa}$ to $720 \mathrm{MPa}$. With the addition of $\operatorname{Pr}_{6} \mathrm{O}_{11}$, the elongation of the weld metal first increased and then decreased. The $0 \% \operatorname{Pr}_{6} \mathrm{O}_{11}$ had the lowest elongation, which was $17 \%$. The $2 \% \operatorname{Pr}_{6} \mathrm{O}_{11}$ had the highest elongation, which was $20 \%$. The $-40{ }^{\circ} \mathrm{C}$ impact toughness of the deposited metal is shown in Figure 2. With the addition of $\operatorname{Pr}_{6} \mathrm{O}_{11}$, the impact toughness increased at first and then decreased. When $1 \% \operatorname{Pr}_{6} \mathrm{O}_{11}$ was added, the impact toughness reached the maximum of $72 \mathrm{~J}$.

\subsection{In Situ Observation of the Formation of $A F, U B$ and Martensite}

The in situ observation of the growth process of ferrite, bainite and martensite with different $\operatorname{Pr}_{6} \mathrm{O}_{11}$ content is shown in Figures 7-9. It can be seen from Figure 7 that when 
$\operatorname{Pr}_{6} \mathrm{O}_{11}$ is not added, AF nucleates and grows on the inclusions, and UB nucleates and grows at the austenite grain boundary and then gradually occupies the space for austenite. Usually, the nucleation temperature of acicular ferrite in weld metal is $40-70{ }^{\circ} \mathrm{C}$ higher than that of bainite [20]. Therefore, acicular ferrite preferentially surrounds intragranular inclusions in the cooling process, thereby inhibiting the bainite transformation that can subsequently occur at prior austenite grain boundaries. In addition, the formed acicular ferrite interface can also stimulate the formation of secondary acicular ferrite. When the acicular ferrite laths nucleate and grow on the inclusions, the increase in the austenite/ferrite interface area can promote the nucleation of acicular ferrite, and the subsequent acicular ferrite nucleation provides a new austenite/ferrite interface, and such excited nucleation can make the distribution of acicular ferrite formed within the austenite grains relatively uniform [1]. The quantity of inclusions in the austenite grains is reduced due to the agglomeration of inclusions at the grain boundaries, so the growth of UB is not restricted, which leads to an increase in the proportion of UB in the austenite and poor impact toughness of the deposited metal. Figure 8 shows that when $1 \% \operatorname{Pr}_{6} \mathrm{O}_{11}$ is added, AF in the grain boundaries first nucleates and grows on the inclusions, divides the austenite grains into many smaller and separated regions, and limits the subsequent formation of UB and martensite growth. As a result, the percentage of AF in the grains is greater than that of UB and martensite, thereby optimizing the impact toughness of the deposited metal.
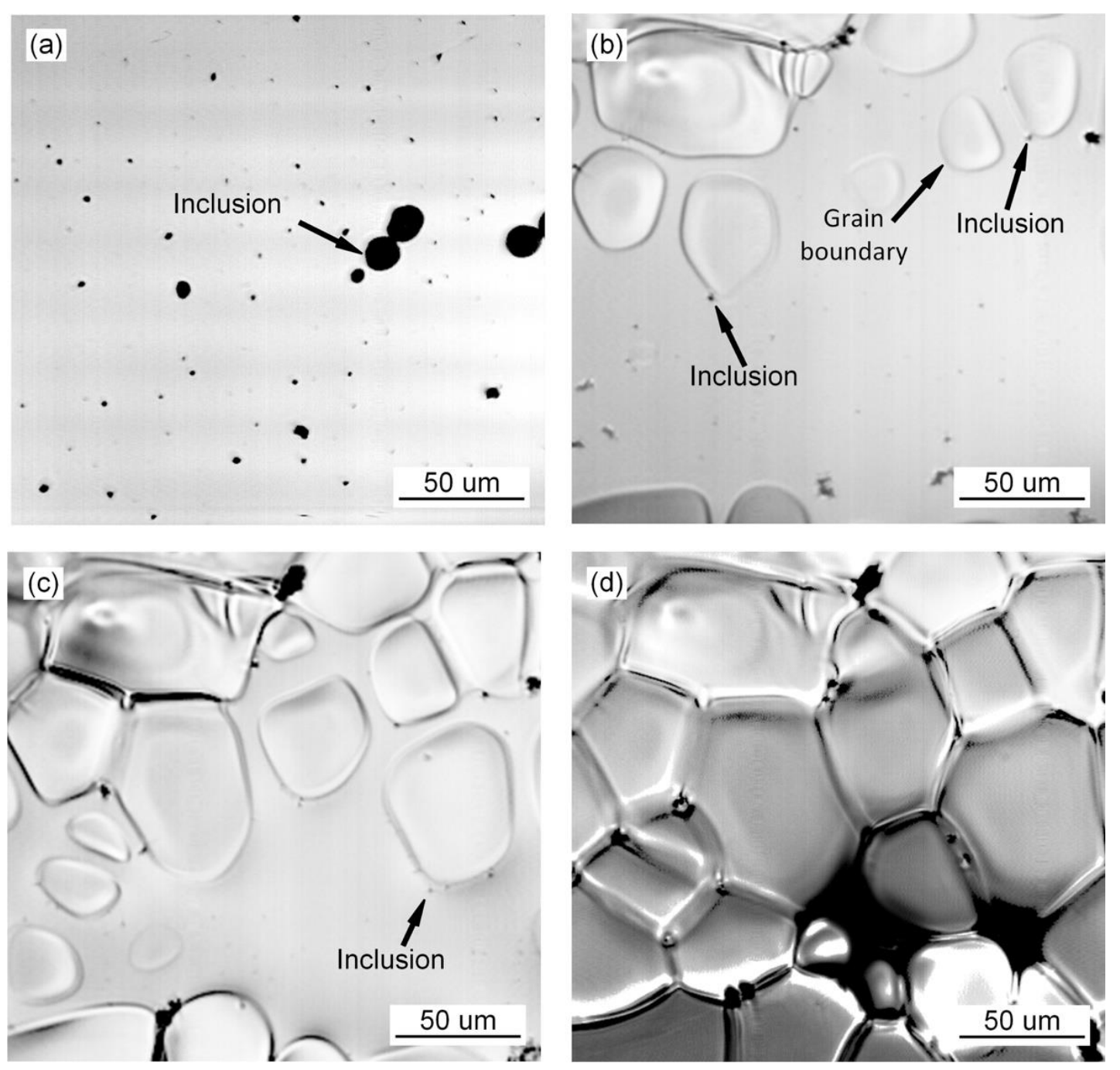

Figure 2. In situ observation of growth process of austenite at $1 \% \operatorname{Pr}_{6} \mathrm{O}_{11}$ : (a) $227.11 \mathrm{~s}, 1545.3{ }^{\circ} \mathrm{C}$; (b) $308.51 .92 \mathrm{~s}, 1424.7^{\circ} \mathrm{C}$; (c) $310.71 \mathrm{~s}, 1410.7^{\circ} \mathrm{C}$; (d) $314.10 \mathrm{~s}, 1387.2^{\circ} \mathrm{C}$. 
(a)

I

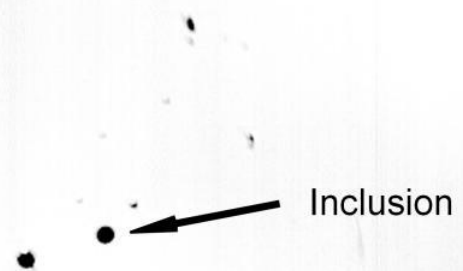

1

$50 \mathrm{um}$

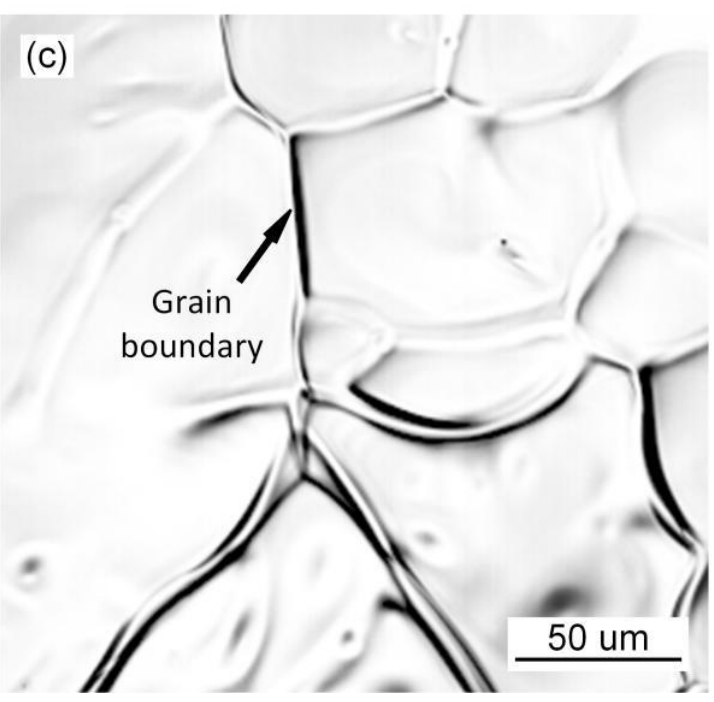

(b)

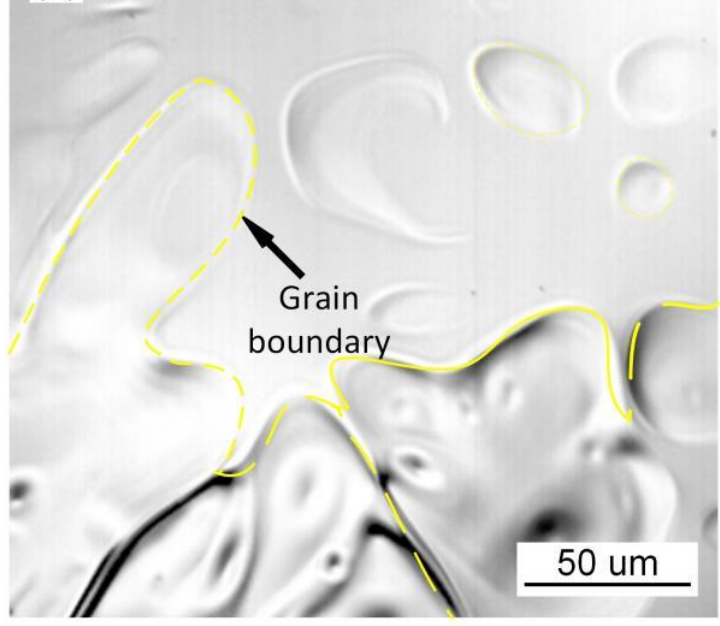

Figure 3. In situ observation of growth process of austenite at $2 \% \operatorname{Pr}_{6} \mathrm{O}_{11}$ : (a) $229.51 \mathrm{~s}, 1486.1^{\circ} \mathrm{C}$; (b) $235.9 \mathrm{~s}, 1459^{\circ} \mathrm{C}$; (c) $236.4 \mathrm{~s}, 1450.9^{\circ} \mathrm{C}$.

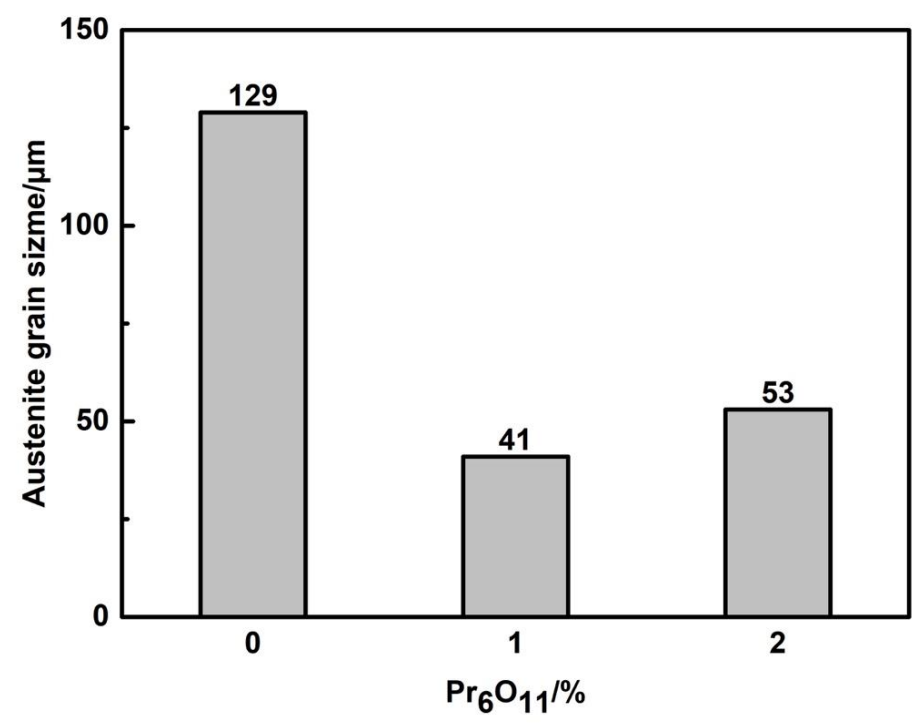

Figure 4. Average size of austenite grains with different $\operatorname{Pr}_{6} \mathrm{O}_{11}$ content. 


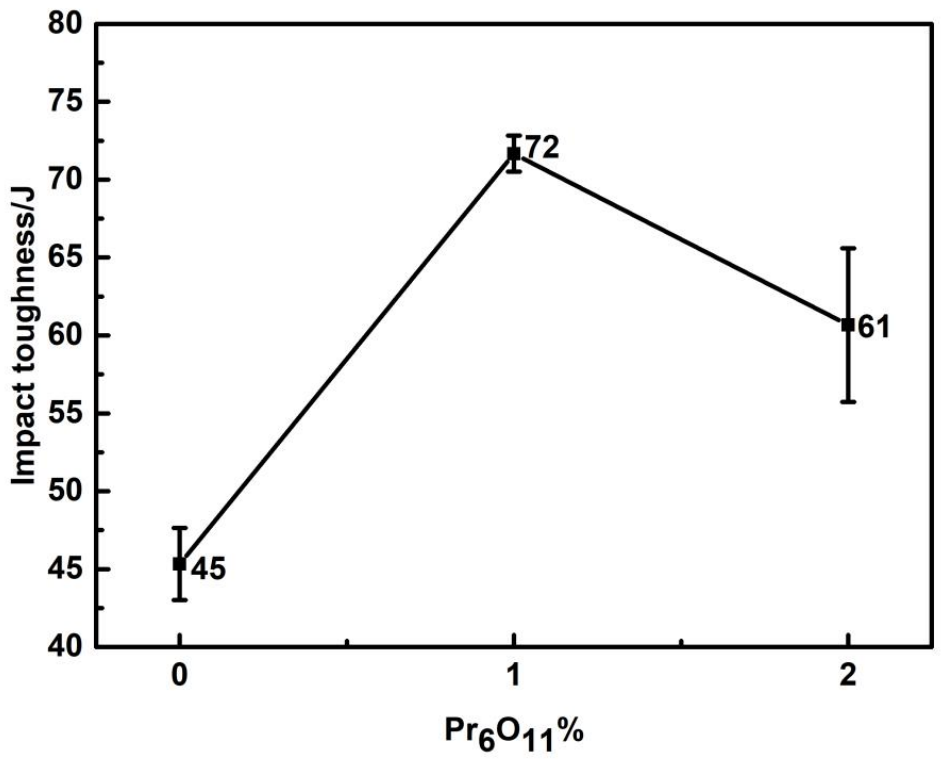

Figure 5. Effect of $\operatorname{Pr}_{6} \mathrm{O}_{11}$ on the impact absorbed energy of the deposited metals.

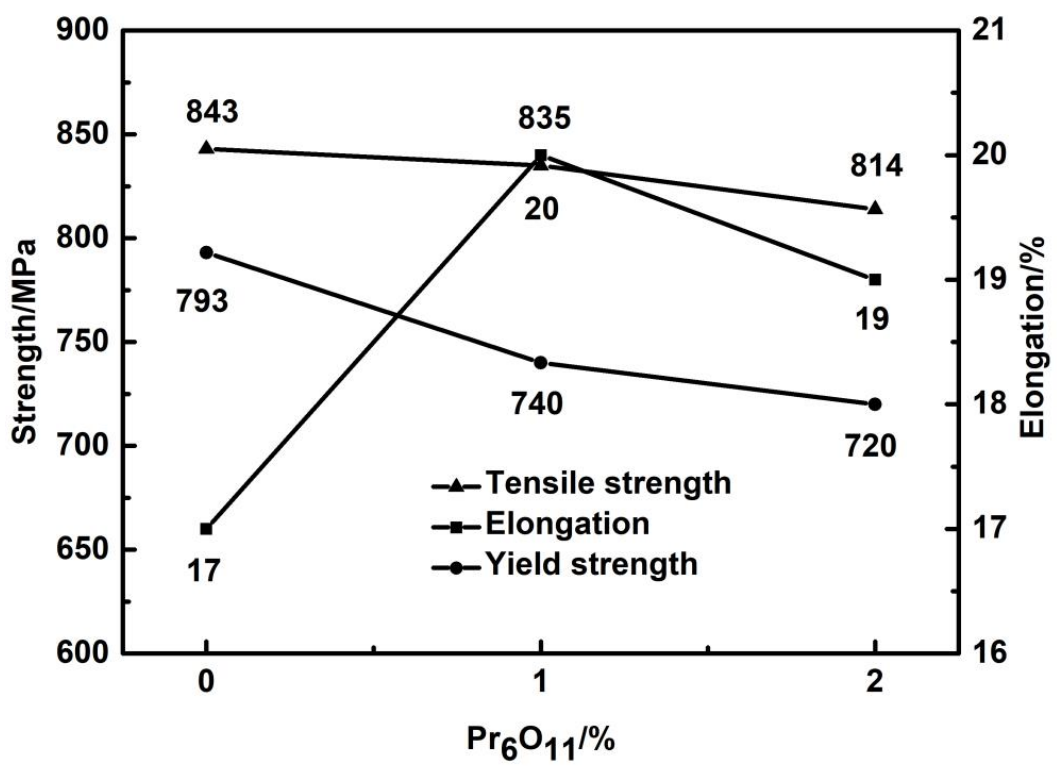

Figure 6. Effect of $\operatorname{Pr}_{6} \mathrm{O}_{11}$ on the strength and elongation of the deposited metals.

Figure 9 shows that when $2 \% \operatorname{Pr}_{6} \mathrm{O}_{11}$ is added, the inclusion nucleation particles are reduced due to the decrease in oxygen, resulting in a decrease in the AF nucleation rate, so UB and martensite grow unrestricted. As a result, the content of UB and martensite in the grain boundary is higher, and the impact toughness of the deposited metal is reduced.

Figures 10-12 show the microstructure and quantitative statistical analysis of deposited metals with different $\operatorname{Pr}_{6} \mathrm{O}_{11}$ content. It can be found that the content of AF first increases and then decreases with the addition of $\operatorname{Pr}_{6} \mathrm{O}_{11}$. When $\operatorname{Pr}_{6} \mathrm{O}_{11}$ is not added, the highest UB content is $46 \%$, and the lower AF content is $28 \%$. The average length of plates of UB and martensite is $51 \mu \mathrm{m}$ and $46 \mu \mathrm{m}$. When $1 \% \operatorname{Pr}_{6} \mathrm{O}_{11}$ is added, the highest percentage of AF is $52 \%$; while the content of UB and martensite is the lowest, $21 \%$ and $27 \%$, the average length of plates of UB and martensite is $32 \mu \mathrm{m}$ and $28 \mu \mathrm{m}$. This is the because the addition of $1 \% \operatorname{Pr}_{6} \mathrm{O}_{11}$ promotes the nucleation and growth of $\mathrm{AF}$, inhibits the growth of UB and martensite, and generates the formation of an interlaced multiphase microstructure. AF preferentially nucleates and separates the austenite, so that the subsequently formed UB 
and martensite do not grow too large to realize grain refinement. When $2 \% \operatorname{Pr}_{6} \mathrm{O}_{11}$ is added, the content of AF decreases to $29 \%$, the content of UB and martensite increases and the average length of plates of UB and martensite is $53 \mu \mathrm{m}$ and $39 \mu \mathrm{m}$. The microstructure of the deposited metal is not uniform, and the lath structure increases. Figure 13 is the schematic diagram of the growth process of the ferrite, bainite and martensite in deposited metals with different $\operatorname{Pr}_{6} \mathrm{O}_{11}$ contents. It can be seen from Figure $13 \mathrm{a}$ that when $\operatorname{Pr}_{6} \mathrm{O}_{11}$ is not added, inclusions in the grains are reduced due to the accumulation of inclusions in the grain boundary, so the nucleation sites of AF are reduced. Thus, the growth of $\mathrm{UB}$ and martensite is not restricted. As the content of UB and martensite increases, the toughness reaches as low as $45 \mathrm{~J}$. Figure $13 \mathrm{~b}$ shows that when $1 \% \operatorname{Pr}_{6} \mathrm{O}_{11}$ is added, the inclusions are dispersed in the austenite grain boundary, and AF nucleation sites increase. A large amount of AF nucleates and grows in grain boundaries, and divides the austenite, so the subsequent growth of UB and martensite is restricted, and an interlaced multiphase microstructure is formed. The impact toughness of the deposited metal is improved to $72 \mathrm{~J}$. It can be seen from the schematic diagram in Figure $13 \mathrm{c}$ that when an excessive amount of $2 \% \operatorname{Pr}_{6} \mathrm{O}_{11}$ is added, the decrease in inclusions leads to a reduction of AF nucleation in austenite grains, resulting in the unrestricted growth of UB and martensite. As the UB and martensite increase, the impact toughness of the deposited metal is reduced to $61 \mathrm{~J}$. With the addition of $\operatorname{Pr}_{6} \mathrm{O}_{11}$ from $1 \%$ to $2 \%$, the proportion of $\mathrm{AF}$ decreases from $52 \%$ to $29 \%$, and the proportion of $\mathrm{UB}$ and $\mathrm{M}$ increases from $27 \%$ and $21 \%$ to $38 \%$ and $33 \%$, respectively, resulting in a decrease in toughness. However, the addition of $\operatorname{Pr}_{6} \mathrm{O}_{11}$ has little effect on the tensile strength of the deposited metal, which is about $810-840 \mathrm{MPa}$.

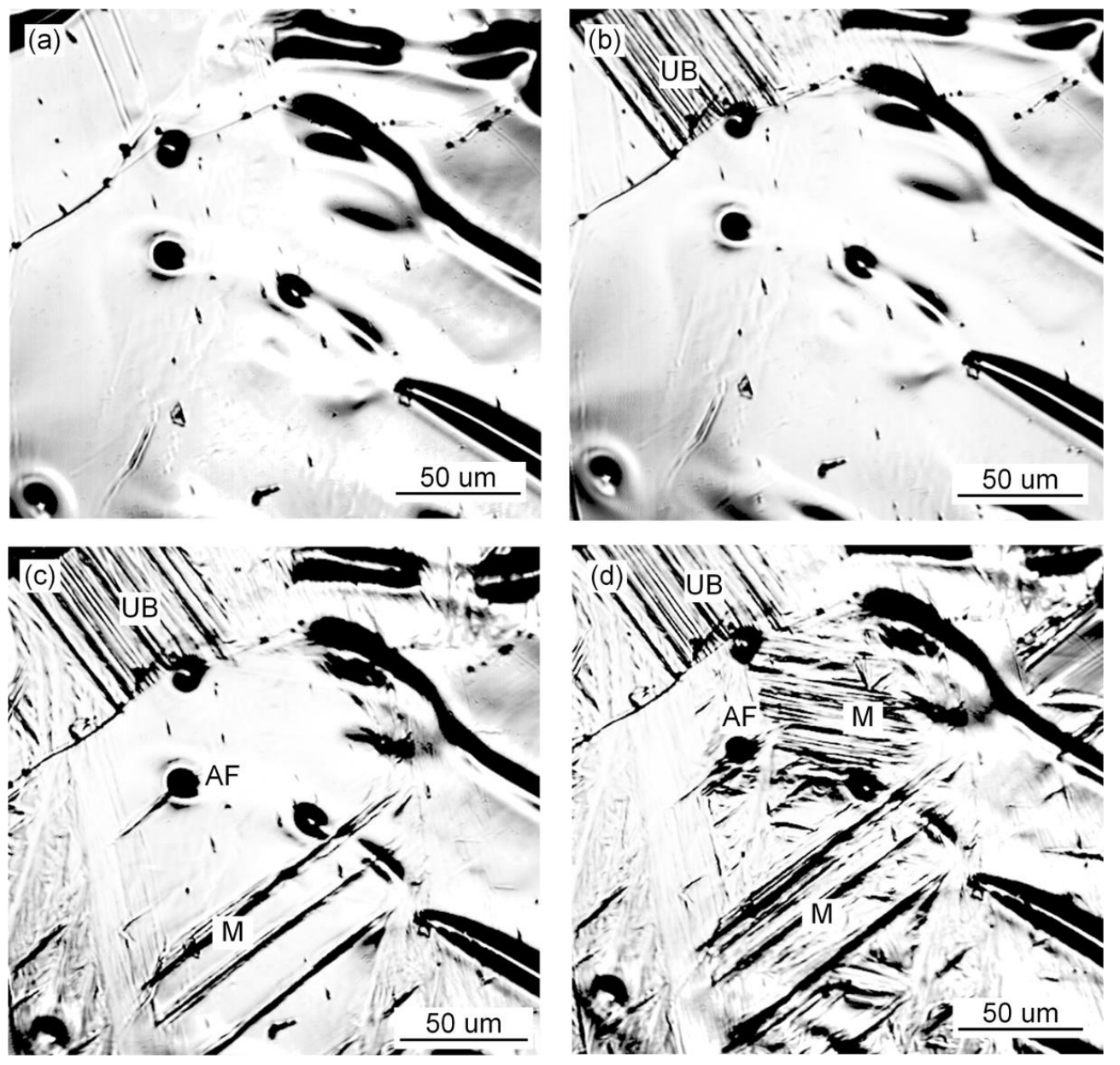

Figure 7. In situ observation of growth process of ferrite, bainite and martensite at $0 \% \operatorname{Pr}_{6} \mathrm{O}_{11}$ : (a) $887.93 \mathrm{~s}, 537^{\circ} \mathrm{C}$; (b) $890.92 \mathrm{~s}, 523^{\circ} \mathrm{C}$; (c) $893.51 \mathrm{~s}, 511^{\circ} \mathrm{C}$; (d) $897.30 \mathrm{~s}, 497.8^{\circ} \mathrm{C}$. 

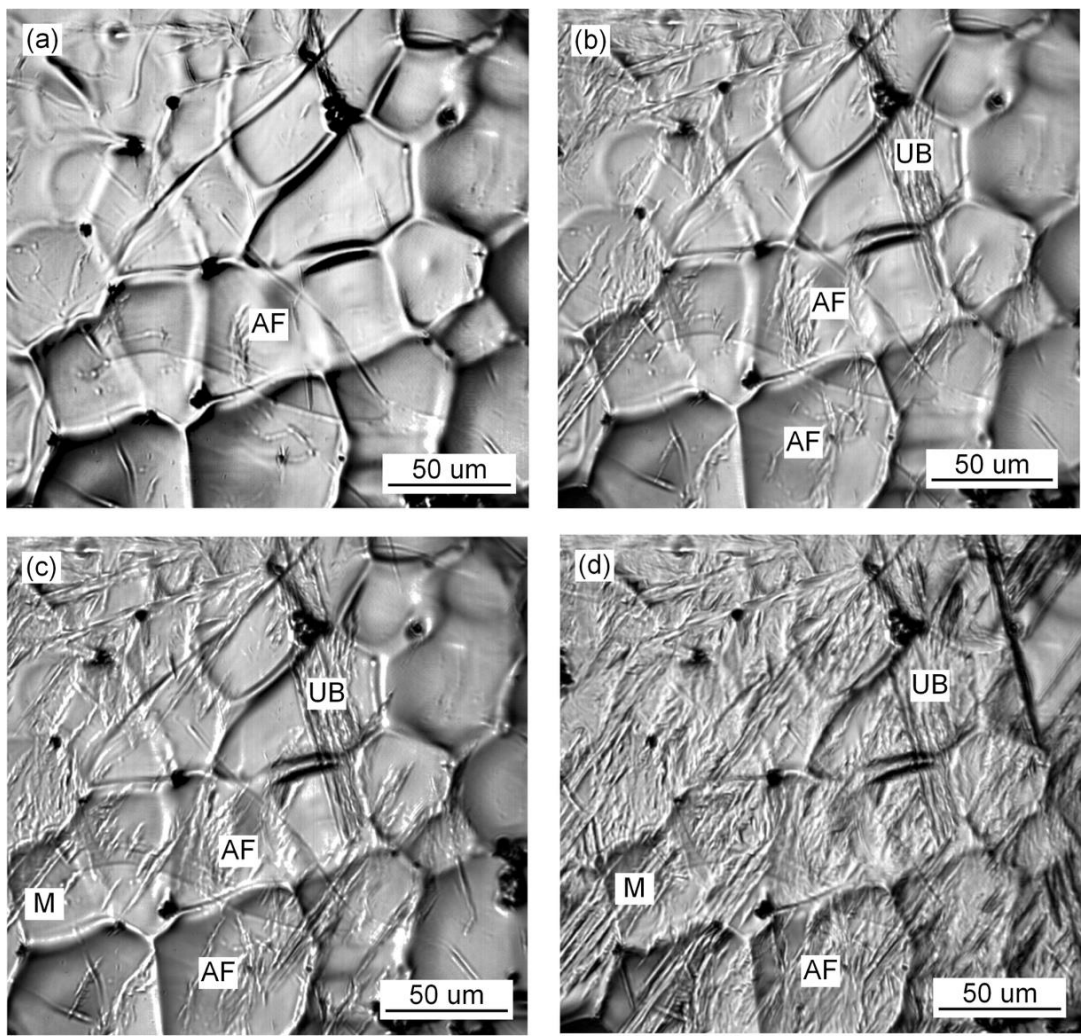

Figure 8. In situ observation of growth process of ferrite, bainite and martensite at $1 \% \operatorname{Pr}_{6} \mathrm{O}_{11}$ : (a) $480.9 \mathrm{~s}, 549.3^{\circ} \mathrm{C}$; (b) $482.68 \mathrm{~s}, 537.4^{\circ} \mathrm{C}$; (c) $483.68 \mathrm{~s}, 530.9^{\circ} \mathrm{C}$; (d) $486.47 \mathrm{~s}, 516.1{ }^{\circ} \mathrm{C}$.
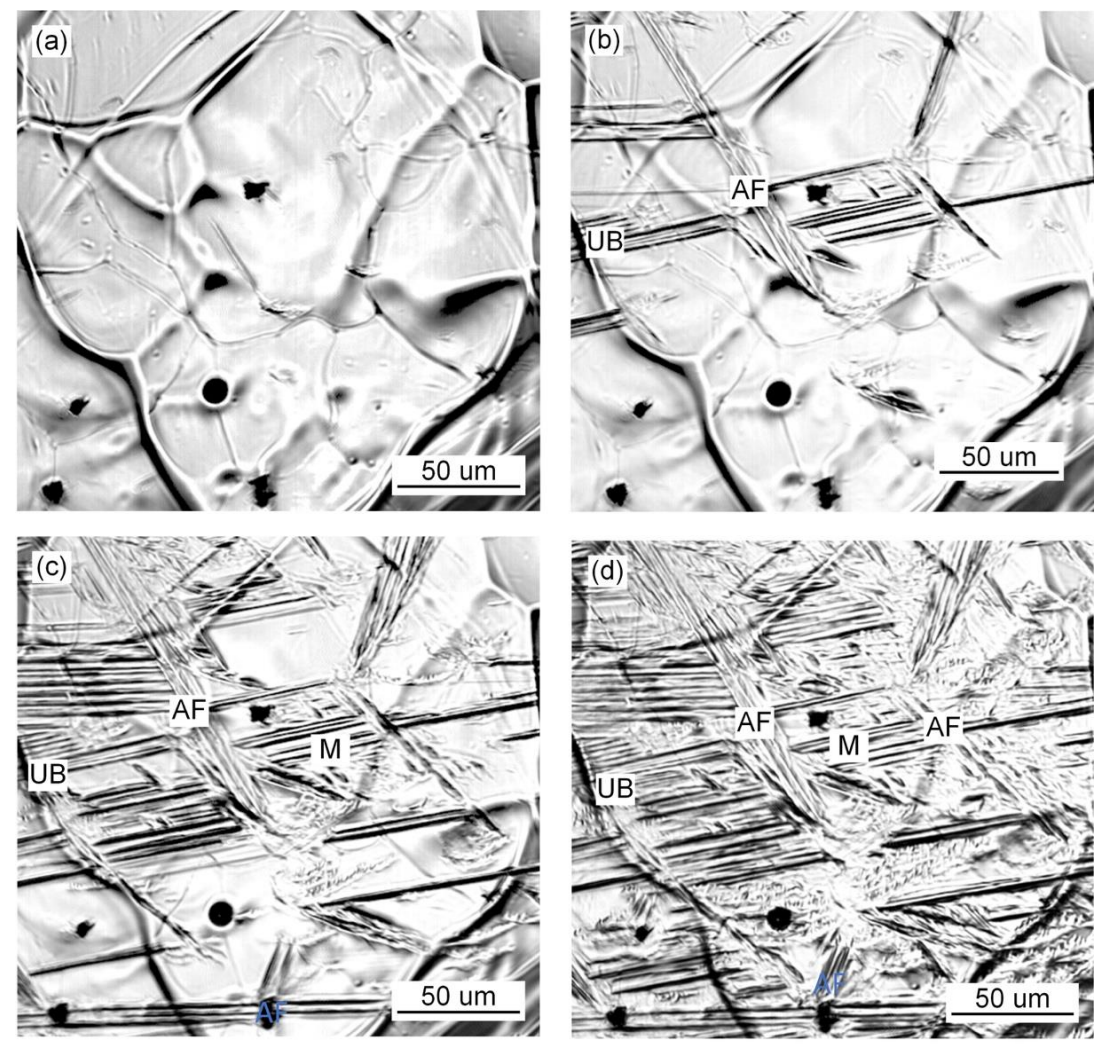

Figure 9. In situ observation of growth process of ferrite, bainite and martensite at $2 \% \operatorname{Pr}_{6} \mathrm{O}_{11}$ : (a) $408.47 \mathrm{~s}, 573{ }^{\circ} \mathrm{C}$; (b) $411.86 \mathrm{~s}, 552.8^{\circ} \mathrm{C}$; (c) $414.25 \mathrm{~s}, 540.9^{\circ} \mathrm{C}$; (d) $418.84 \mathrm{~s}, 522.6^{\circ} \mathrm{C}$. 


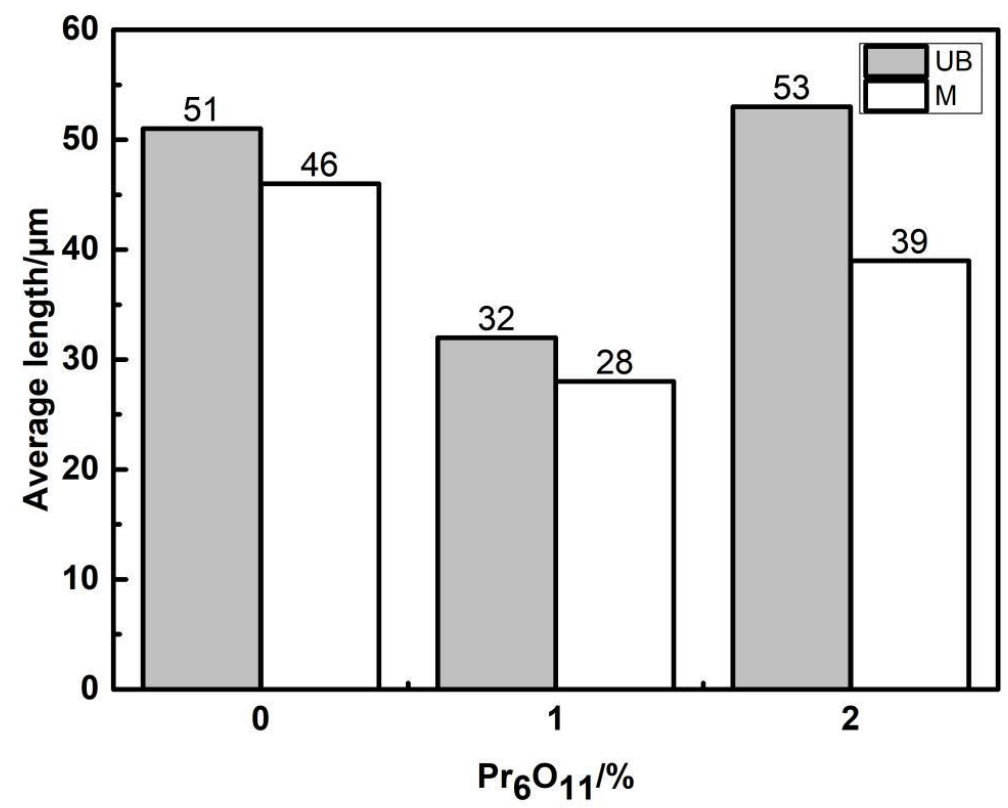

Figure 10. The average length of plates of UB and martensite.
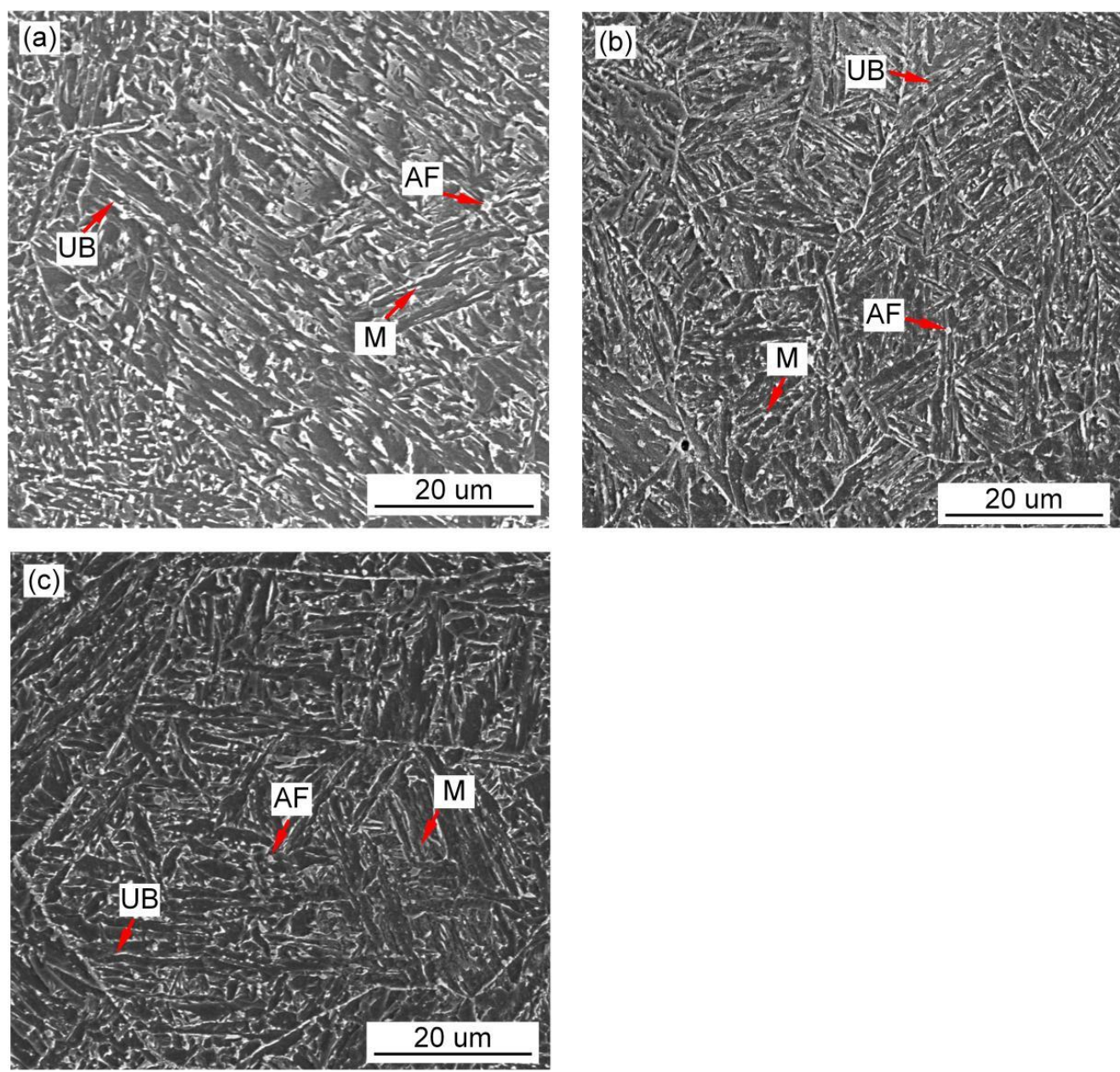

Figure 11. SEM images of microstructure of deposited metals with different $\operatorname{Pr}_{6} \mathrm{O}_{11}$ content: (a) $0 \% \operatorname{Pr}_{6} \mathrm{O}_{11}$; (b) $1 \% \operatorname{Pr}_{6} \mathrm{O}_{11} ;$ (c) $2 \% \operatorname{Pr}_{6} \mathrm{O}_{11}$. 


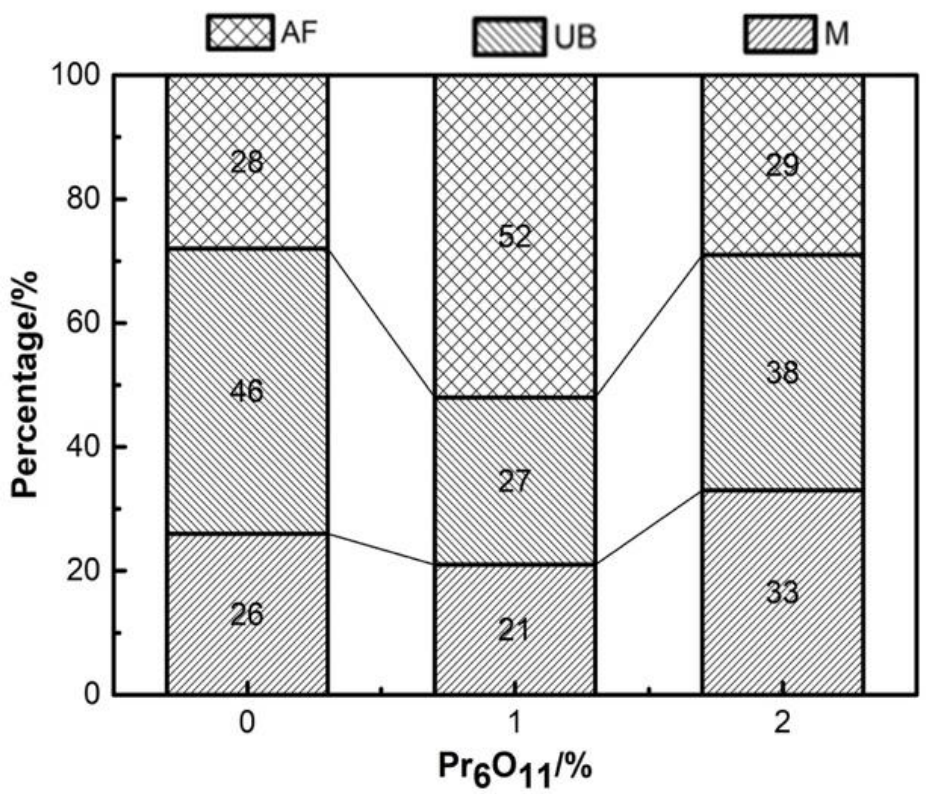

Figure 12. Quantitative statistical diagram of deposited metals with different $\operatorname{Pr}_{6} \mathrm{O}_{11}$ content.

(a)

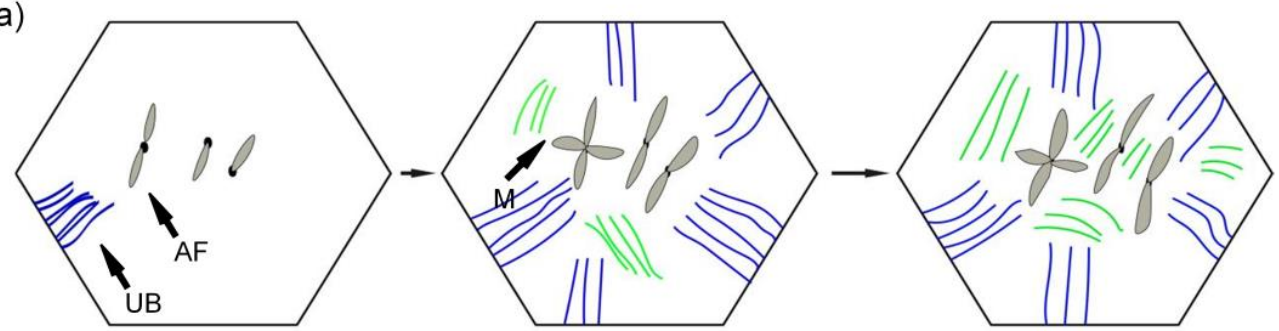

(b)

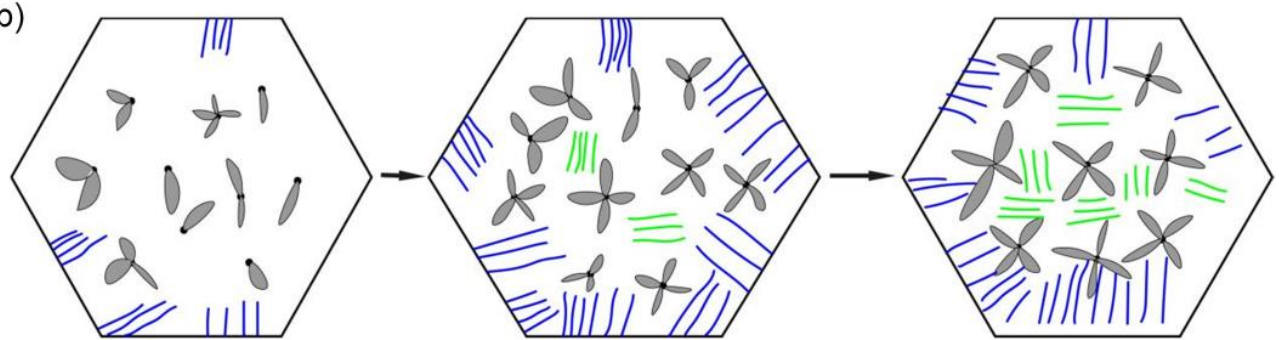

(c)

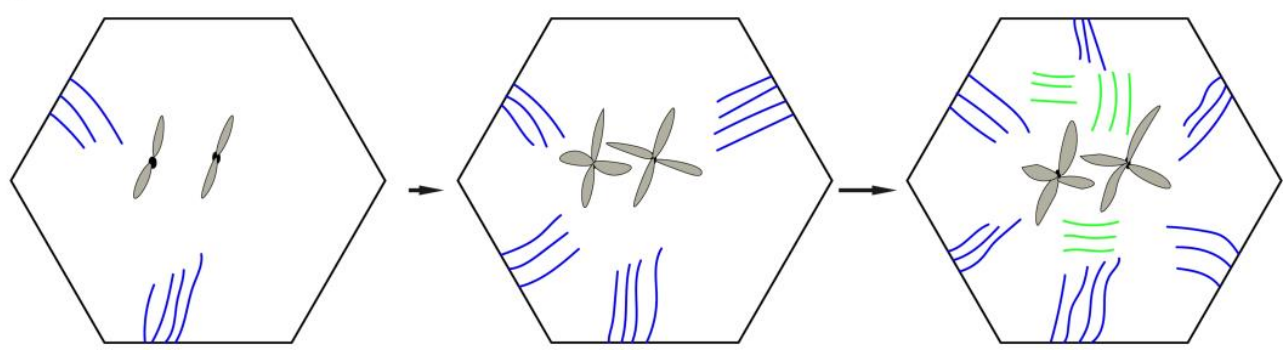

Figure 13. Schematic diagram of growth process of ferrite, bainite and martensite with different $\operatorname{Pr}_{6} \mathrm{O}_{11}$ content: (a) $0 \% \operatorname{Pr}_{6} \mathrm{O}_{11} ;$ (b) $1 \% 0 \% \operatorname{Pr}_{6} \mathrm{O}_{11} ;$ (c) $2 \% 0 \% \operatorname{Pr}_{6} \mathrm{O}_{11}$.

Since the solid phase transition during the welding process is continuous and complex, the microstructure of the deposited metal is complex and uneven. As the temperature of the deposited metal changes, AF nucleates and grows prior to UB and martensite at high temperature, and divides the original austenite grains into several parts. The subsequently 
generated UB and martensite can only grow in the segmented region. In the formed interlaced multiphase microstructure, each grain has various orientations and the size of the grain is small. The cracks need to change many times when passing through this microstructure. Passivation or branching occurs at the large-angle grain boundary formed between UB and AF. More energy is consumed, so the deposited metal has excellent impact toughness. The grain size of the original austenite has been determined at high temperature. The more the divided structure of the complex phase is generated by the subsequent phase transformation, the more complex the degree of interlacing, and the more excellent strength and toughness of the deposited metal. UB and martensite act as the main strengthening phase, and AF acts as the main toughening phase. It can be seen from Figure 11a that the microstructure of the deposited metal without adding $\operatorname{Pr}_{6} \mathrm{O}_{11}$ is basically a single orientation. However, Figure $11 \mathrm{~b}$ shows that with the addition of $1 \% \operatorname{Pr}_{6} \mathrm{O}_{11}$, the deposited metal has more interlaced multiphase microstructures with different orientations. This explains why the impact toughness of deposited metal is significantly higher with $1 \% \operatorname{Pr}_{6} \mathrm{O}_{11}$ than without $\operatorname{Pr}_{6} \mathrm{O}_{11}$.

AF is considered to be an excellent microstructural component that improves toughness by effectively refining grains. AF grains can divide the coarse austenite grains into small single regions, forming a mixed structure of fine particles. The microstructure of AF has larger angled grain boundaries, which can effectively increase the crack propagation path during fracture. The increase in the energy required for crack propagation helps to improve the low temperature impact toughness of the weld metal, which may explain why the impact energy of deposited metal without $\operatorname{Pr}_{6} \mathrm{O}_{11}$ is higher than that of deposited metal with $1 \% \operatorname{Pr}_{6} \mathrm{O}_{11}$. The addition of $\operatorname{Pr}_{6} \mathrm{O}_{11}$ can serve as the core of AF heterophasic nucleation. The grain core preferentially attaches to the surface of these impurities and promotes the formation of a large amount of AF, which inhibits the formation of phases such as martensite and UB. Martensite and UB are the main strengthening phases, which can increase the strength and hardness of the weld metal. AF is the toughening phase in the weld metal, which mainly improves the low temperature impact toughness of the weld metal [16]. The formation of AF reduces the martensite and UB strengthening phases in the weld metal, so the addition of $\operatorname{Pr}_{6} \mathrm{O}_{11}$ leads to a decrease in strength and an increase in toughness.

Therefore, $\operatorname{Pr}_{6} \mathrm{O}_{11}$ mainly improves the toughness of deposited metal through the following three aspects: firstly, rare earth Pr promotes the nucleation of AF and inhibits the growth of UB and M; secondly, rare earth inhibits the growth of original austenite grains during the welding; thirdly, the deposited metal forms an interlaced multiphase microstructure with different orientations. Rare earth elements can improve the mechanical properties of deposited metal, mainly by changing the aggregation status of inclusions, making inclusions dispersed in the deposited metal to pin the austenite grain boundary and limit the growth of austenite. It also helps to promote the nucleation and growth of AF and divide the austenite, so that the subsequent growth of UB and martensite is restricted, forming an interlaced multiphase microstructure and improving the impact toughness of the deposited metal. However, the amount of $\operatorname{Pr}_{6} \mathrm{O}_{11}$ added should be controlled. Excessive addition will reduce the oxygen content in the deposited metal, reduce the content of inclusions and AF nucleation sites, thereby reducing the impact toughness of the deposited metal of high-strength steel.

\subsection{Inclusions in Deposited Metals}

Figures 14-17 show the SEM images, high-temperature laser scanning confocal microscopy images, EDS analysis and size statistics of inclusions in the deposited metals with different $\operatorname{Pr}_{6} \mathrm{O}_{11}$ content. Without adding $\operatorname{Pr}_{6} \mathrm{O}_{11}$, the inclusions are mainly composed of $\mathrm{Fe}, \mathrm{O}, \mathrm{Si}, \mathrm{Mn}, \mathrm{Ti}, \mathrm{Al}$ and $\mathrm{Zn}$. The inclusions are mainly Mn-Si-Zn oxide. The inclusion size is mainly distributed between $1.2-1.8 \mu \mathrm{m}$; the average size of the inclusion is $1.725 \mu \mathrm{m}$ and $0.89 \%$ in area. The inclusions agglomerate irregularly, which is not conducive to the formation of AF [21,22]. 

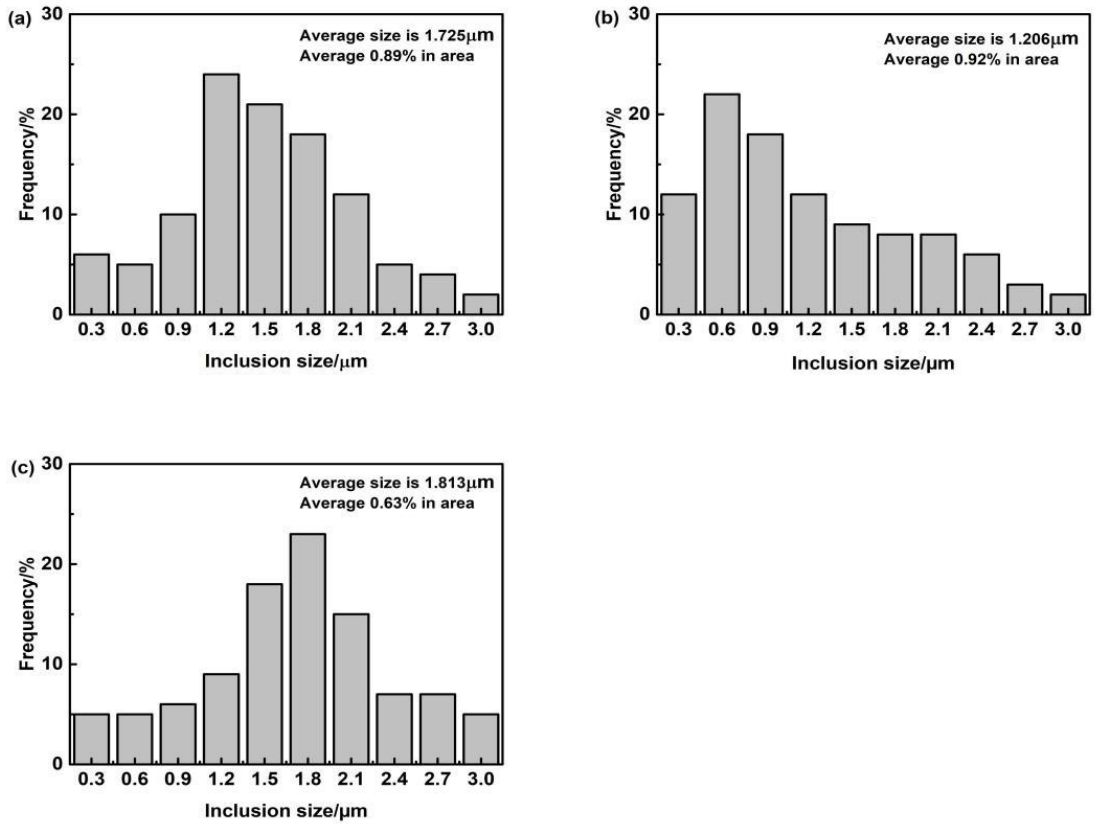

Figure 14. The size distribution of inclusions in deposited metals with different $\operatorname{Pr}_{6} \mathrm{O}_{11}$ content: (a) $0 \% \operatorname{Pr}_{6} \mathrm{O}_{11} ;$ (b) $1 \% \operatorname{Pr}_{6} \mathrm{O}_{11} ;$ (c) $2 \% \operatorname{Pr}_{6} \mathrm{O}_{11}$.
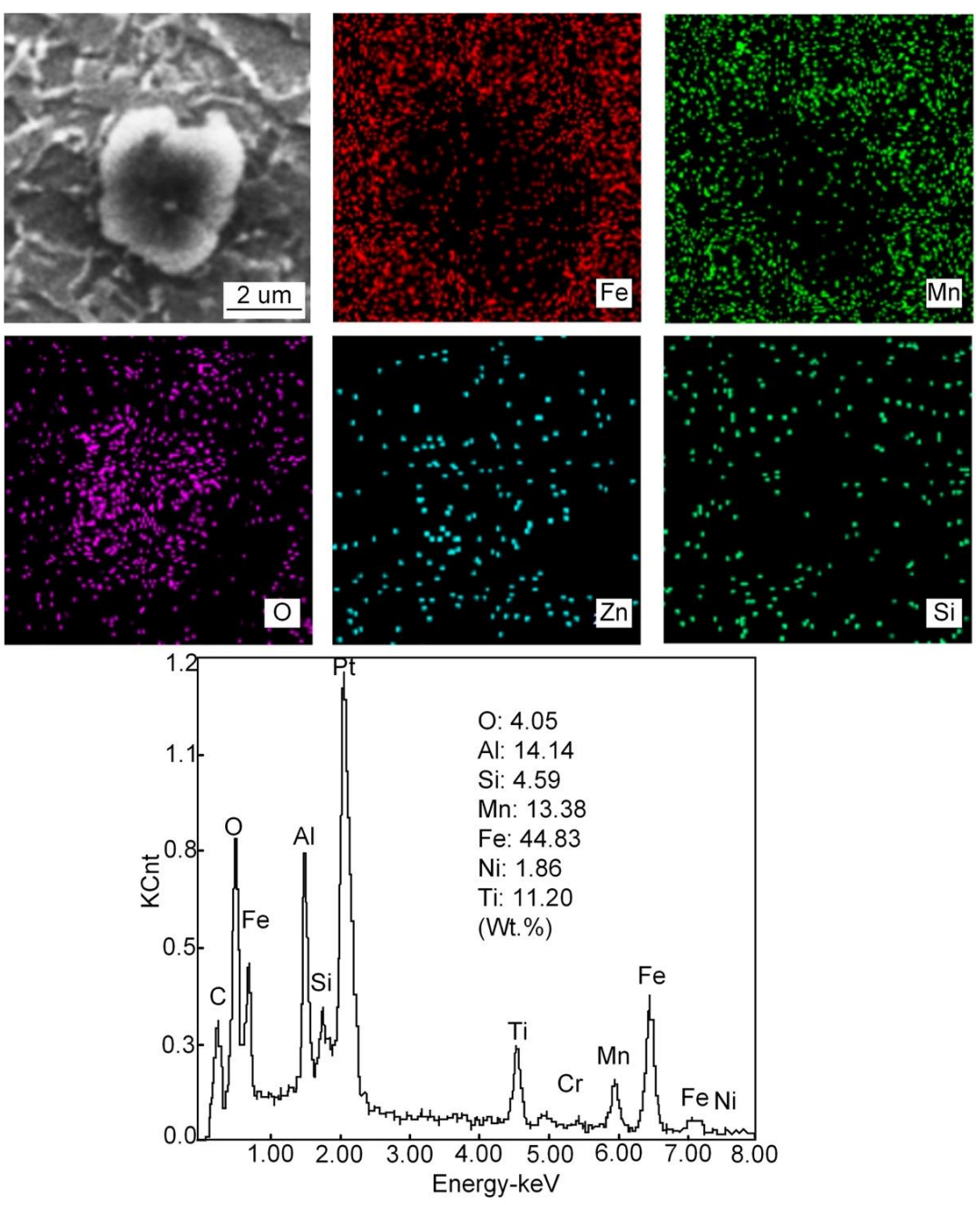

Figure 15. EDS analysis of inclusions in deposited metal at $0 \% \operatorname{Pr}_{6} \mathrm{O}_{11}$. 

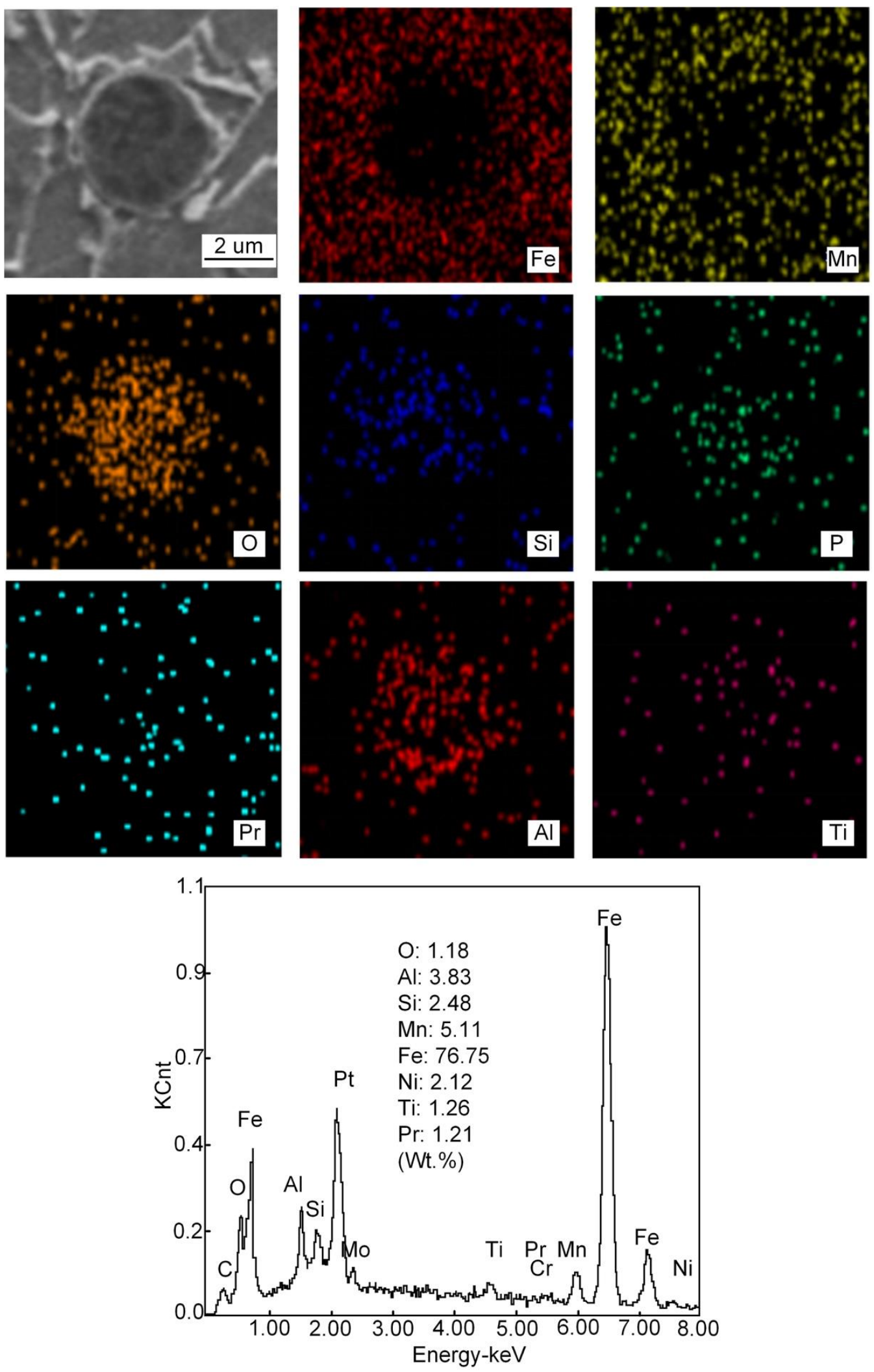

Figure 16. EDS analysis of inclusions in deposited metal at $1 \% \operatorname{Pr}_{6} \mathrm{O}_{11}$. 

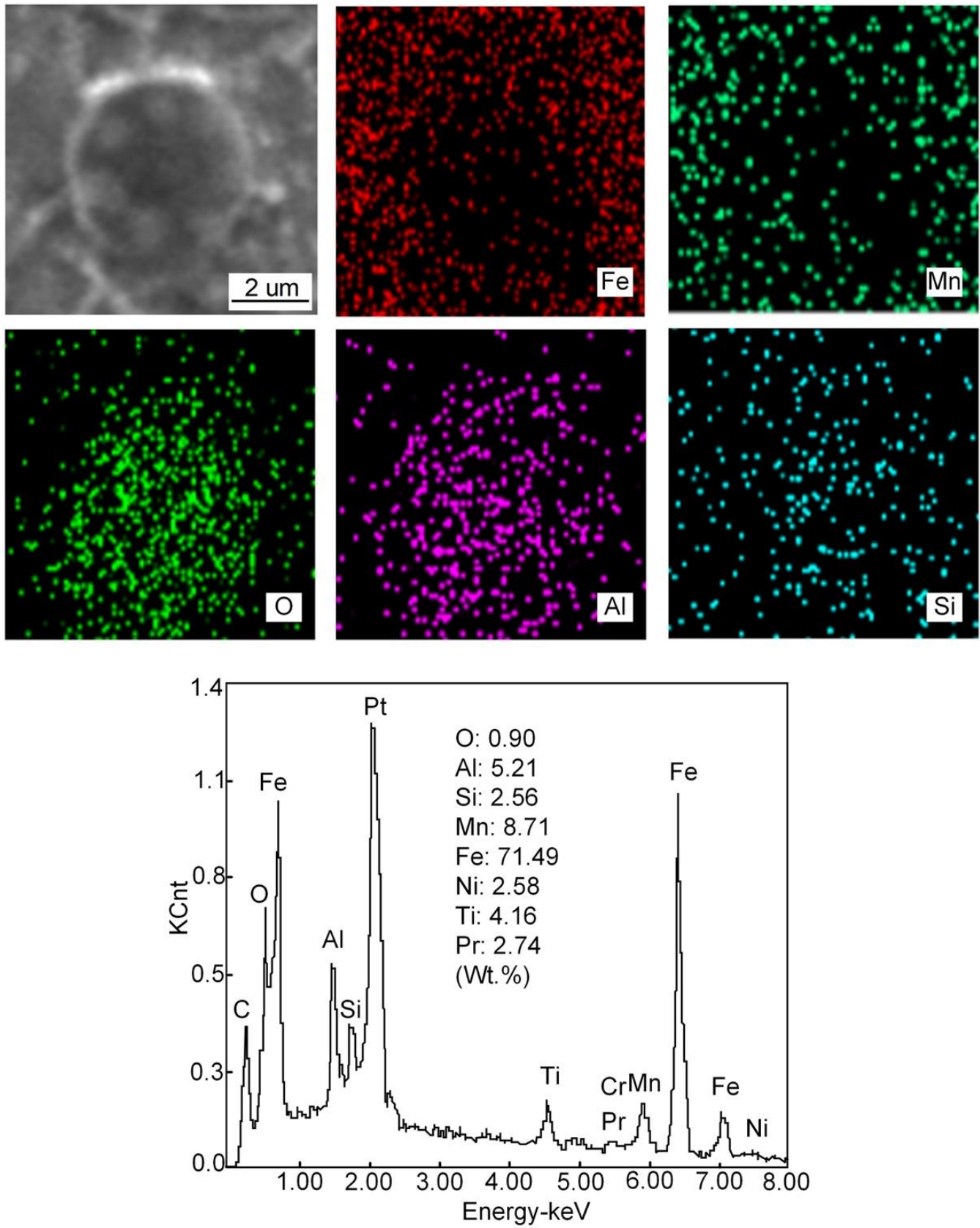

Figure 17. EDS analysis of inclusions in deposited metal at $2 \% \operatorname{Pr}_{6} \mathrm{O}_{11}$.

When $1 \% \operatorname{Pr}_{6} \mathrm{O}_{11}$ is added, the inclusion is mainly composed of $\mathrm{Fe}, \mathrm{O}, \mathrm{Si}, \mathrm{Mn}, \mathrm{Ti}, \mathrm{Al}$, Pr and $\mathrm{Cr}$, and the size is mainly distributed in the range $0.6-1.5 \mu \mathrm{m}$; the average size of the inclusion is $1.206 \mu \mathrm{m}$ and $0.92 \%$ in area. Zhang et al. [20] pointed out that most of the inclusions used as AF nucleation were between 0.4 and $1.6 \mu \mathrm{m}$ in size, and they were composite inclusions containing multiple elements. Therefore, adding $1 \% \operatorname{Pr}_{6} \mathrm{O}_{11}$ inclusion size is conducive to AF nucleation and growth. In addition, the inclusions present a dispersive distribution, are small in size and their shape is spherical or elliptical. This indicates that the addition of $1 \% \operatorname{Pr}_{6} \mathrm{O}_{11}$ promotes the refinement and spheroidization of the inclusions. Pr was found in the deposited metal and the inclusions are cored with $\mathrm{Si}-\mathrm{Al}-\mathrm{Ti}-\mathrm{Pr}$ oxides and covered by an outer layer of Mn-Fe oxides. It was found that the inclusions in the deposited metal changed from the long strip of a larger size to the spherical or elliptical of a smaller size [23]. 
When $2 \% \operatorname{Pr}_{6} \mathrm{O}_{11}$ is added, the inclusion mainly consists of $\mathrm{Fe}, \mathrm{O}, \mathrm{Si}, \mathrm{Mn}, \mathrm{Ti}, \mathrm{Al}, \mathrm{Pr}$ and $\mathrm{Cr}$. The inclusion size is mainly distributed in the range 1.5-2.1 $\mathrm{m}$; the average size of the inclusion is $1.813 \mu \mathrm{m}$ and $0.63 \%$ in area. The inclusions are cored with $\mathrm{Al}$ oxides and covered by an outer layer of $\mathrm{Mn}$ oxides. The $\mathrm{O}$ content in the inclusions is reduced from $1.18 \%$ to $0.90 \%$, and the quantity of inclusions is significantly reduced. This is because that the deoxidation of the rare earth element Pr leads to a decrease in O content in the inclusions, and the formation of inclusions in the deposited metal is closely related to the $\mathrm{O}$ content [24]. The addition of rare earth affects $\mathrm{O}$ content in the deposited metal, which in turn affects the formation of inclusions. Therefore, the excessive addition of $\operatorname{Pr}_{6} \mathrm{O}_{11}$ may inhibit the formation of inclusions in the deposited metal; the decrease in inclusions leads to a reduction in AF nucleation in austenite grains, resulting in the unrestricted growth of UB and martensite.

The main mechanism of AF nucleation is the formation of an element depletion zone around inclusions. In the Pr-free deposited metal, only a small amount of AF grains nucleate on some inclusions. The inclusion consists of $\mathrm{Al}, \mathrm{Ti}, \mathrm{Mn}$ and $\mathrm{O}$ elements. It is observed that the inclusions are complex oxides of $\mathrm{Al}$ and $\mathrm{Ti}$ wrapped in $\mathrm{MnO}$, which usually lead to the formation of a poor Mn zone due to the precipitation of $\mathrm{MnO}$. The fundamental mechanism of AF nucleation in Pr-free deposited metal is the depletion of Mn near inclusions. The formation of a manganese-poor zone increases the phase transition temperature and nucleation driving energy, thus promoting the nucleation of AF grains. Compared with the Pr-free deposited metal, there are more AF grains nucleated in the inclusions in $1 \% \operatorname{Pr}_{6} \mathrm{O}_{11}$, and the inclusions are characterized by composite oxides of $\mathrm{Al}$ and Ti covering $\mathrm{MnO}$ and $\operatorname{Pr}_{6} \mathrm{O}_{11}$. The presence of $\operatorname{Pr}_{6} \mathrm{O}_{11}$ in the vicinity of complex inclusions has contributed to the formation of high density of AF grains [9]. When $2 \% \operatorname{Pr}_{6} \mathrm{O}_{11}$ is added, the inclusion mainly consists of $\mathrm{Fe}, \mathrm{O}, \mathrm{Si}, \mathrm{Mn}, \mathrm{Ti}, \mathrm{Al}, \mathrm{Pr}$ and $\mathrm{Cr}$. The inclusion size is mainly distributed between $1.5-2.1 \mu \mathrm{m}$.

The addition of $\operatorname{Pr}_{6} \mathrm{O}_{11}$ in the deposited metal will promote the transformation of inclusions and form rare earth composite inclusions. With the addition of $\operatorname{Pr}_{6} \mathrm{O}_{11}$ in the deposited metal, the inclusion phases in spherical forms normally have the maximum surface tension under the premise of the same volume. The spherical inclusions have the minimum thermodynamic driving force during their growing process in the weld pool [25]. Thus the inclusions in the deposited metal change their shape.

With $\mathrm{Al}_{2} \mathrm{O}_{3}$ in the inclusions, the addition of rare earth will promote the formation of uniform Pr-Al-O rare earth composite inclusions [26,27]. During the cooling process of deposited metal, $\mathrm{Pr}_{6} \mathrm{O}_{11}$ reacts with $\mathrm{Ti}_{2} \mathrm{O}_{3}$ and $\mathrm{Al}_{2} \mathrm{O}_{3}$ inclusion particles to form rare earth composite inclusions. The diameter of the inclusions gradually increases, and the core of the inclusions transforms into Mn-Si-Pr-Al-Ti-O composite inclusions. The existence of Si and $\mathrm{Mn}$ in the inclusions is caused by the absorption of Si and $\mathrm{Mn}$ in the base metal and welding wire during the growth of inclusions. Mn in the inclusions is also an important factor affecting AF nucleation [28-31].

\subsection{Crystallographic Characteristics of Microstructure in Deposited Metal}

Figure 18 is the EBSD orientation maps of the microstructures of deposited metals with different $\operatorname{Pr}_{6} \mathrm{O}_{11}$ content. Figure $18 \mathrm{a}, \mathrm{b}$ is the inverse pole image of the subunit structure of the microstructure. It can be seen from the inverse pole image that the austenite grains are divided into several orientations, and the microstructures of different orientations are intertwined. This intertwined structure is beneficial to suppress crack propagation and improve the toughness of the material. Figure 19 is a statistical diagram of the size and angle of grain boundaries in the microstructure of deposited metals with different $\operatorname{Pr}_{6} \mathrm{O}_{11}$ contents. The size of grains without $\operatorname{Pr}_{6} \mathrm{O}_{11}$ is mainly distributed in the range 4-8 $\mu \mathrm{m}$. With adding $1 \% \operatorname{Pr}_{6} \mathrm{O}_{11}$, the grain size becomes smaller, mainly distributed in the range 3-5 $\mu \mathrm{m}$; with a small angle grain boundary $\left(0^{\circ}-15^{\circ}\right)$, the quantity of grains is significantly reduced, and the number of large-angle grain boundaries (grain boundaries greater than $15^{\circ}$ ) is increased. When the crack crosses the large-angle grain boundary and enters adjacent 
grains, it inevitably changes the direction of crack propagation. Crack propagation will be hindered as it consumes energy during the process, so the impact toughness of deposited metal will increase [32]. The energy of a small-angle grain boundary is low, and the dislocation structure of the grain boundary is simple, so cracks can pass through easily, therefore reducing the impact toughness of the deposited metal. AF is considered to be an excellent microstructural component that improves toughness by effectively refining grains. AF grains can divide the coarse austenite grains into small single regions, forming a mixed structure of fine particles. The microstructure of AF has larger-angled grain boundaries. Therefore, with the addition of $\operatorname{Pr}_{6} \mathrm{O}_{11}$, the proportion of acicular ferrite increases so that the high-angle grain boundaries in the deposited metal increase. The reasons for the improvement in impact toughness of the deposited metal with the addition of $1 \% \operatorname{Pr}_{6} \mathrm{O}_{11}$ include: firstly, the grain size is reduced, and the grains become refined; secondly, the quantity of small-angle grain boundaries decreases significantly, and crack propagation is hindered as a result of the increase in large-angle grain boundaries.
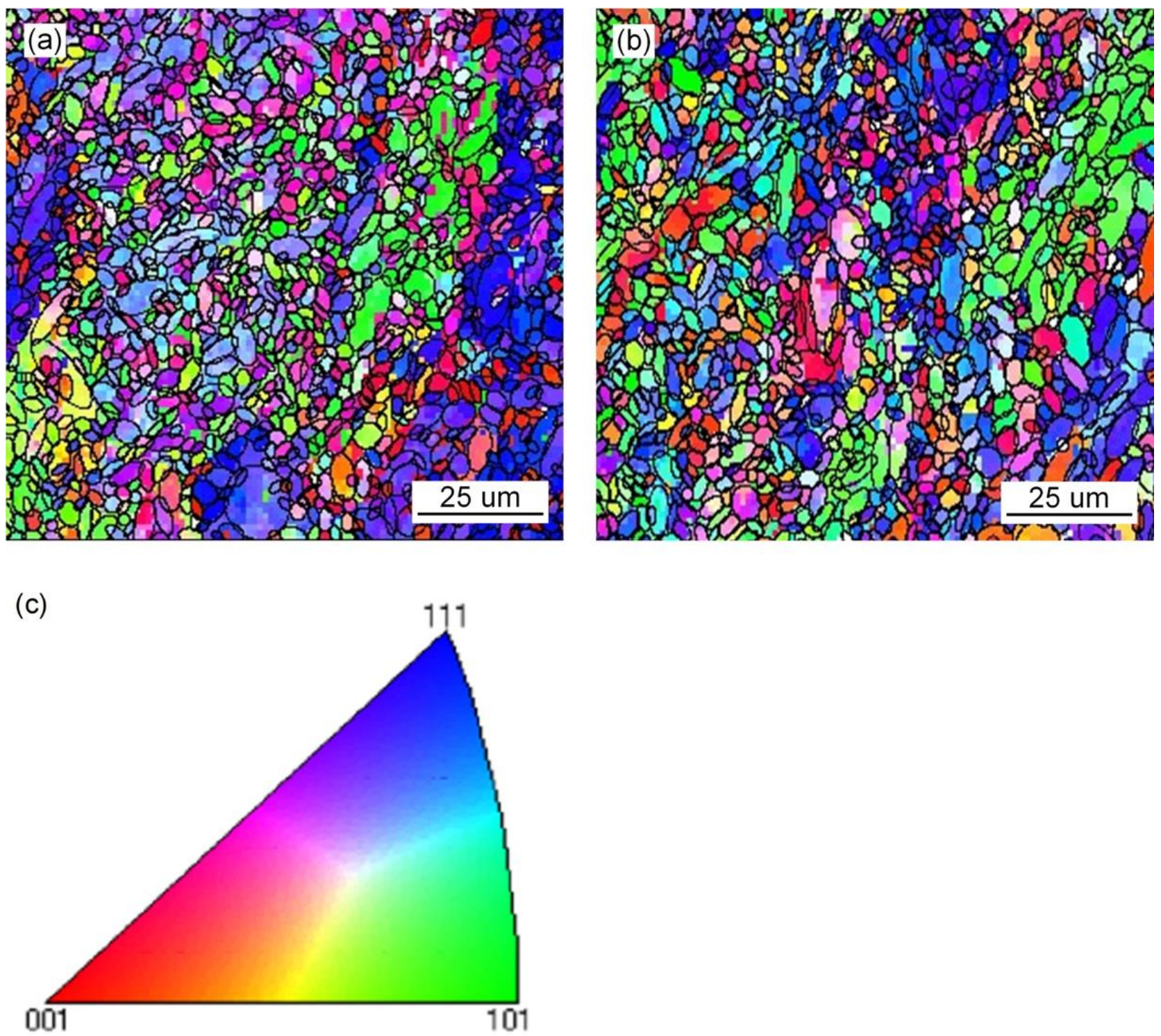

Figure 18. EBSD orientation maps of microstructure of deposited metals with different $\operatorname{Pr}_{6} \mathrm{O}_{11}$ content: (a) $0 \% \operatorname{Pr}_{6} \mathrm{O}_{11}$; (b) $1 \% \operatorname{Pr}_{6} \mathrm{O}_{11}$; (c) orientation color key. 

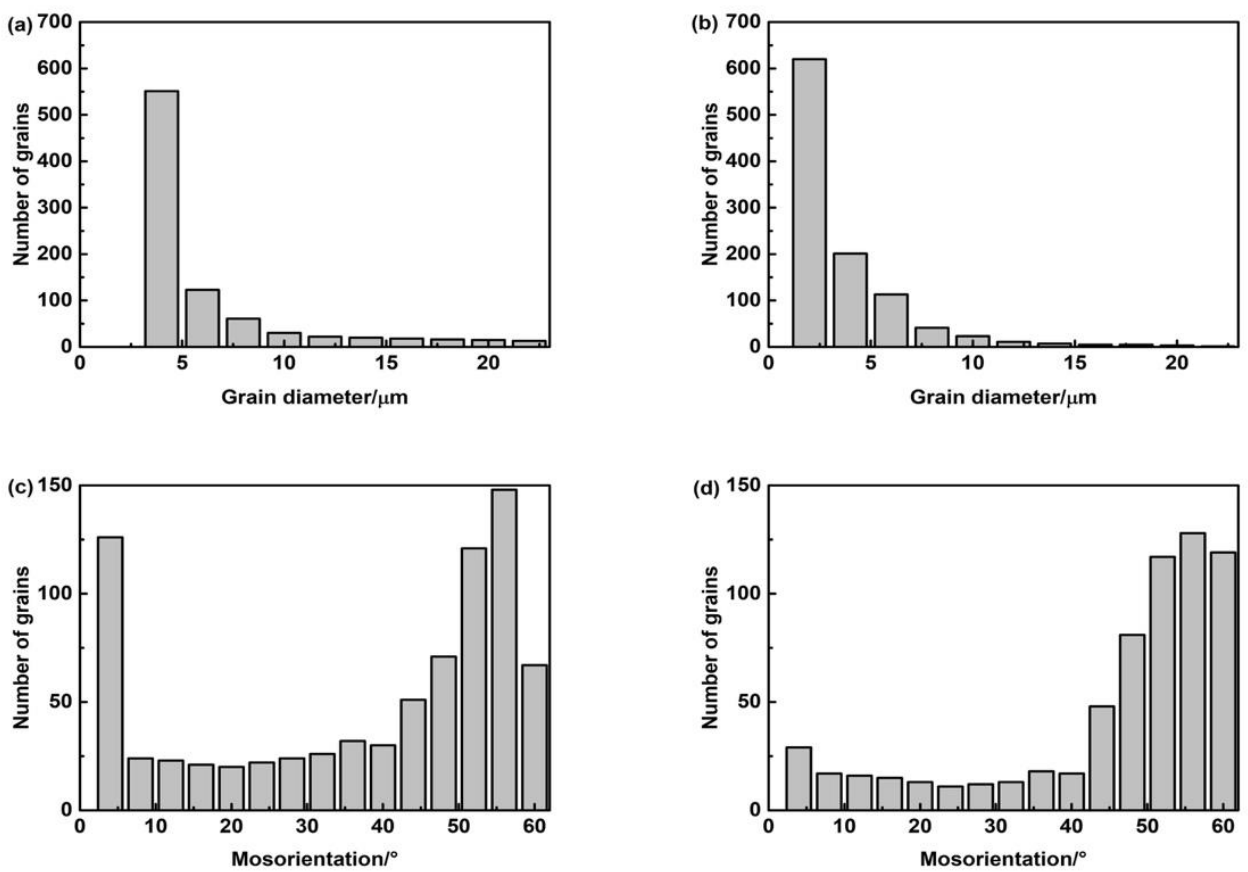

Figure 19. EBSD statistics of microstructure of deposited metals with different $\operatorname{Pr}_{6} \mathrm{O}_{11}$ content: (a) $0 \% \operatorname{Pr}_{6} \mathrm{O}_{11}$ size distribution; (b) $1 \% \operatorname{Pr}_{6} \mathrm{O}_{11}$ size distribution; (c) $0 \% \operatorname{Pr}_{6} \mathrm{O}_{11}$ grain angle distribution; (d) $1 \% \operatorname{Pr}_{6} \mathrm{O}_{11}$ grain angle distribution.

\section{Conclusions}

Compared with no addition of $\operatorname{Pr}_{6} \mathrm{O}_{11}$, adding $1 \% \operatorname{Pr}_{6} \mathrm{O}_{11}$ can change the inclusion aggregation from agglomeration at the grain boundary to dispersed distribution within austenite grains. The size of the inclusions becomes smaller, and their shapes are spherical or elliptical. The inclusions pin the original austenite grain boundaries so as to effectively inhibit the growth of austenite grains. The size of inclusions is mainly distributed in the range $0.6-1.5 \mu \mathrm{m}$, which is conducive to the formation of AF nucleation particles. AF nucleates and grows on the inclusions, divides the austenite grains and restricts the growth of UB and martensite, forming an interlaced multiphase microstructure.

After adding $1 \% \mathrm{Pr}_{6} \mathrm{O}_{11}$ in the deposited metals, the average size of austenite grains was at a minimum $(41 \mu \mathrm{m})$. Small-angle grain boundaries were reduced and large-angle grain boundaries increased. The tensile strength of the deposited metal reached $834 \mathrm{MPa}$, and the maximum impact toughness reached $72 \mathrm{~J}$.

The inclusions in the deposited metal were Mn-Si-Pr-Al-Ti and Mn-Si-Pr-Al-Ti-O in the free-Pr and Pr contents of the deposited metals. The average size of inclusions decreased after Pr addition. These composite inclusions effectively induced the formation of AF.

With the addition of $2 \% \operatorname{Pr}_{6} \mathrm{O}_{11}$, excessive rare earth elements caused the austenite grains to coarsen; the inclusion size was mainly distributed in the range 1.5-2.1 $\mu \mathrm{m}$. AF nucleation sites were reduced, thereby reducing AF. The growth of UB and martensite were unrestricted, resulting in a reduction in the impact toughness of the deposited metal to $61 \mathrm{~J}$.

Author Contributions: Conceptualization, T.Z.; methodology, W.W., Y.M. and N.F.; software, W.W.; validation, T.Z., W.W. and Z.L.; formal analysis, T.Z. and W.W.; investigation, W.W., S.L., Z.L. and S.K.; resources, T.Z. and W.W.; data curation, Y.M. and N.F.; writing-original draft preparation, T.Z. and W.W.; writing-review and editing, S.L. and Z.L.; visualization, W.W. and N.F.; supervision, T.Z.; project administration, T.Z.; funding acquisition, T.Z. All authors have read and agreed to the published version of the manuscript.

Funding: The authors gratefully acknowledge the financial support provided by the National Natural Science Foundation of China (Grant No. 51804196) and State Key Laboratory of Advanced Welding and Joining, Harbin Institute of Technology (Grant No. AWJ-22M18). 


\section{Institutional Review Board Statement: Not applicable.}

Informed Consent Statement: Not applicable.

Data Availability Statement: The data presented in this study are available on request from the corresponding author.

Conflicts of Interest: The authors declare no conflict of interest.

\section{References}

1. Zhang, T.L.; Yu, H.; Li, Z.X.; Kou, S.; Kim, H.J.; Tillmann, W. Progress on effects of alloying elements on bainite formation and strength and toughness of high strength steel weld metal. Mater. Res. Express 2021, 8, 032002. [CrossRef]

2. Liu, C.; Bhole, S.D. Challenges and developments in pipeline weldability and mechanical properties. Sci. Technol. Weld. Join. 2013, 18, 169-181. [CrossRef]

3. Mohrbacher, $\mathrm{H}$. Combined effects of $\mathrm{Nb}$ and B microalloying in molybdenum based ultra low carbon bainitic steels. J. Iron Steel Res. Int. 2011, 18, 806-812.

4. Wen, T.; Hu, X.F.; Yan, D.S.; Rong, L.J. Effect of V contents on microstructure and mechanical properties in a Fe-Cr-Ni-Mo high-strength steel. Mater. Sci. Forum 2014, 788, 304-310. [CrossRef]

5. Hu, T.W.; Hu, X.F.; Song, Y.Y.; Yan, D.S.; Rong, L.J. Carbides and mechanical properties in a Fe-Cr-Ni-Mo high-strength steel with different V contents. Mater. Sci. Eng. A 2013, 588, 201-207.

6. Wan, X.L.; Wu, K.M.; Gang, H.; Wen, R.; Cheng, L. In situ observation of austenite grain growth behavior in the simulated coarse-grained heat-affected zone of Ti-microalloyed steels. Int. J. Min. Met. Mater. 2014, 21, 878-885. [CrossRef]

7. Liu, Y.; Li, G.Q.; Wan, X.L.; Zhang, X.G.; Shen, Y.; Wu, K.M. Toughness improvement by Zr addition in the simulated coarsegrained heat-affected zone of high-strength low-alloy steels. Ironmak. Steelmak. 2017, 46, 1-11. [CrossRef]

8. Huang, G.; Wan, X.L.; Wu, K.M.; Zhao, H.Z.; Misra, R.D.K. Effects of small Ni addition on the microstructure and toughness of coarse-grained heat-affected zone of high-strength low-alloy steel. Metals 2018, 8, 718. [CrossRef]

9. Wan, X.L.; Wu, K.M.; Huang, G.; Nune, K.C.; Li, Y.; Cheng, L. Toughness improvement by Cu addition in the simulated coarse-grained heat-affected zone of high-strength low-alloy steels. Sci. Technol. Weld. Join. 2016, 21, 295-302. [CrossRef]

10. Zhang, M.; Wang, Q.; Li, J.H.; Zhi, J.H.; Luo, H.L. Microstructure numerical simulation of weld pool in rapid solidification. Trans. China Weld. Inst. 2013, 34, 1-4.

11. Xu, L.Y.; Yang, J.; Wang, R.Z.; Wang, W.L.; Ren, Z.M. Effect of welding heat input on microstructure and toughness of heatedaffected zone in steel plate with $\mathrm{Mg}$ deoxidation. Steel Res. Int. 2017, 88, 1700157. [CrossRef]

12. Li, H.; Liang, J.L.; Feng, Y.L.; Huo, D.X. Microstructure transformation of X70 pipeline steel welding heat-affected zone. Rare Metals 2014, 33, 493-498. [CrossRef]

13. Yang, K.; Wang, F.; Duan, D.S.; Zhang, T.L.; Luo, C.G.; Cressault, Y.; Yu, Z.S.; Yang, L.J.; Li, H. Experimental investigation of integrated circular triple-wire pulse GMAW of Q960E high-strength steel for construction machinery. Materials 2021, 14, 375. [CrossRef] [PubMed]

14. Chai, F.; Yang, C.F.; Su, H.; Zhang, Y.Q.; Xu, Z. Effect of magnesium on inclusion formation in Ti-killed steels and microstructural evolution in welding induced coarse-grained heat affected zone. J. Iron Steel Res. Int. 2009, 1, 69-74. [CrossRef]

15. Song, S.H.; Sun, H.J.; Wang, M. Effect of rare earth cerium on brittleness of simulated welding heat-affected zones in a reactor pressure vessel steel. J. Rare Earths 2015, 33, 1204-1211. [CrossRef]

16. Cai, Y.C.; Liu, R.P.; Wei, Y.H.; Cheng, Z.G. Influence of Y on microstructures and mechanical properties of high strength steel weld metal. Mater. Des. 2014, 62, 83-89. [CrossRef]

17. Wan, X.L.; Wu, K.M.; Huang, G.; Wei, R. In situ observations of the formation of fine-grained mixed microstructures of acicular ferrite and bainite in the simulated coarse-grained heated-affected zone. Steel Res. Int. 2014, 85, 243-250. [CrossRef]

18. AWS A5.28/A5.28M. Specification for Low-Alloy Steel Electrodes and Rods for Gas Shielded Arc Welding; American National Standards Institute: Miami, FL, USA, 2005.

19. Chung, S.H.; Lee, B.; Lee, S.Y.; Do, C.; Ryu, H.J. The effects of Y pre-alloying on the in-situ dispersoids of ODS CoCrFeMnNi high-entropy alloy. J. Mater. Sci. Technol. 2021, 85, 62-75. [CrossRef]

20. Zhang, T.L.; Li, Z.X.; Young, F.; Kim, H.J.; Li, H.; Jing, H.Y.; Tillmann, W. Global progress on welding consumables for HSLA steel. ISIJ Int. 2014, 54, 1472-1484. [CrossRef]

21. Guo, H.; Yang, S.F.; Wang, T.T.; Yuan, H.; Zhang, Y.L.; Li, J.S. Microstructure evolution and acicular ferrite nucleation in inclusion-engineered steel with modified MgO@C nanoparticle addition. J. Mater. Sci. Technol. 2022, 99, 277-287. [CrossRef]

22. Li, Y.D.; Xing, W.W.; Li, X.B.; Chen, B. Effect of Mg Addition on the Microstructure and Properties of a Heat-Affected Zone in Submerged Arc Welding of an Al-KilledLow Carbon Steel. Materials 2021, 14, 2445. [CrossRef] [PubMed]

23. Wang, J.; Wang, Y.C.; Su, Y.C.; Shi, J. Evaluation of in-situ alloyed Inconel 625 from elemental powders by laser directed energy deposition. Mat. Sci. Eng. A 2021, 14, 2296. [CrossRef]

24. Wegrzyn, T.; Szopa, R.; Miros, M. Non-metallic inclusions in the weld metal deposit of shielded electrodes used for welding of low-carbon and low-alloy steel. Weld. Int. 2009, 23, 54-59. [CrossRef] 
25. Wang, H.; Bao, Y.; Duan, C.; Lu, L.; Liu, Y.; Zhang, Q. Effect of rare earth Ce on deep stamping properties of high-strength interstitial-free steel containing phosphorus. Materials 2020, 13, 1473. [CrossRef] [PubMed]

26. Zhao, X.D.; Dong, J.; Li, B.G.; Li, F.Z. Kinetics of formation of large-dimension rare earth inclusion in steels. J. Rare Earth Engl. Ed. 2004, 22, 403-405.

27. Li, H.; Mclean, A.; Rutter, J.W.; Sommerville, I.D. Influence of rare earth metals on the nucleation and solidification behavior of iron and 1045 steel. Metall. Meter. Trans. B 1988, 19, 383-395. [CrossRef]

28. Huang, X.H.; Huang, X.Y.; Mao, H.K.; Yin, Z.X. Analysis of large-dimension rare earth inclusion in steels by metallographic microscope and TEM. Appl. Mech. Mater. 2012, 183, 288-291.

29. Song, M.M.; Song, B.; Yang, Z.B.; Zhang, S.H.; Hu, C.L. Effects of Mn and Al on the intragranular acicular ferrite formation in rare earth treated C-Mn steel. High Temp. Mater. Process. 2016, 36, 683-691. [CrossRef]

30. Zhang, D.; Terasaki, H.; Komizo, Y.I. In situ observation of the formation of intragranular acicular ferrite at non-metallic inclusions in C-Mn steel. Acta Mater. 2010, 58, 683-691. [CrossRef]

31. Xu, L.Y.; Yang, J.; Park, J.; Ono, H. Mechanism of improving heat-affected zone toughness of steel plate with Mg deoxidation after high-heat-input welding. Metals 2020, 10, 162. [CrossRef]

32. Wang, M.; Song, B.; Wei, Q.S.; Zhang, Y.J.; Shi, Y.S. Effects of annealing on the microstructure and mechanical properties of selective laser melted AlSi7Mg alloy. Mat. Sci. Eng. A 2019, 739, 463-472. [CrossRef] 